\title{
Deep-sequencing transcriptome analysis of chilling tolerance mechanisms of a subnival alpine plant, Chorispora bungeana
}

Zhiguang Zhao ${ }^{1,2+}$, Lingling Tan ${ }^{1 \dagger}$, Chunyan Dang ${ }^{1}$, Hua Zhang ${ }^{1}$, Qingbai $\mathrm{Wu}^{2}$ and Lizhe $\mathrm{An}^{1 *}$

\begin{abstract}
Background: The plant tolerance mechanisms to low temperature have been studied extensively in the model plant Arabidopsis at the transcriptional level. However, few studies were carried out in plants with strong inherited cold tolerance. Chorispora bungeana is a subnival alpine plant possessing strong cold tolerance mechanisms. To get a deeper insight into its cold tolerance mechanisms, the transcriptome profiles of chilling-treated C. bungeana seedlings were analyzed by Illumina deep-sequencing and compared with Arabidopsis.

Results: Two cDNA libraries constructed from mRNAs of control and chilling-treated seedlings were sequenced by Illumina technology. A total of 54,870 unigenes were obtained by de novo assembly, and 3,484 chilling up-regulated and 4,571 down-regulated unigenes were identified. The expressions of 18 out of top 20 up-regulated unigenes were confirmed by qPCR analysis. Functional network analysis of the up-regulated genes revealed some common biological processes, including cold responses, and molecular functions in C. bungeana and Arabidopsis responding to chilling. Karrikins were found as new plant growth regulators involved in chilling responses of C. bungeana and Arabidopsis. However, genes involved in cold acclimation were enriched in chilling up-regulated genes in Arabidopsis but not in C. bungeana. In addition, although transcription activations were stimulated in both C. bungeana and Arabidopsis, no CBF putative ortholog was up-regulated in C. bungeana while CBF2 and CBF3 were chilling up-regulated in Arabidopsis. On the other hand, up-regulated genes related to protein phosphorylation and auto-ubiquitination processes were over-represented in C. bungeana but not in Arabidopsis.

Conclusions: We conducted the first deep-sequencing transcriptome profiling and chilling stress regulatory network analysis of $C$. bungeana, a subnival alpine plant with inherited cold tolerance. Comparative transcriptome analysis suggests that cold acclimation is not a major chilling tolerance mechanism of C. bungeana. Activation of protein phosphorylation and ubiquitination may confer chilling tolerance to $C$. bungeana in a more rapid and flexible way than cold acclimation. Such differences may have contributed to the differences in cold tolerance between C. bungeana and Arabidopsis. The results presented in this paper will be informative for gene discovery and the molecular mechanisms related to plant cold tolerance.
\end{abstract}

Keywords: Alpine plant, Chorispora bungeana, Chilling tolerance, Cold acclimation, Transcriptome

\footnotetext{
* Correspondence: lizhean@|zu.edu.cn

${ }^{\dagger}$ Equal contributors

'Key Laboratory of Cell Activities and Stress Adaptations, Ministry of

Education, School of Life Sciences, Lanzhou University, Lanzhou 730000,

China

Full list of author information is available at the end of the article
}

\section{Biomed Central}

(c) 2012 Zhao et al.; licensee BioMed Central Ltd. This is an Open Access article distributed under the terms of the Creative Commons Attribution License (http://creativecommons.org/licenses/by/2.0), which permits unrestricted use, distribution, and reproduction in any medium, provided the original work is properly cited. 


\section{Background}

Chorispora bungeana Fisch. \& C.A. Mey (C. bungeana) is a perennial subnival alpine plant that can survive freezing temperature [1]. In the natural environments where $C$. bungeana is growing (origin of Urumqi River in Tianshan Mountains, Xinjiang Autonomous Region, China), snowing and hailing often occur during favorable growing seasons, and air temperature fluctuates frequently ranging from above $20^{\circ} \mathrm{C}$ to below $-10^{\circ} \mathrm{C}$. C. bungeana in local environment can survive, grow and flower even in snow. Our previous studies performed at physiological and molecular levels showed that this plant has strong cold (chilling and freezing) tolerance [1-6]. However, little is known about its tolerance mechanisms, if any, distinguishing C. bungeana from other tropical or temperate plants.

Not all plants are always ready to tolerate freezing temperatures. However, studies have shown many plants are tolerant of freezing temperature after exposure to non-freezing low temperature, a phenomenon called cold acclimation $[7,8]$. In such a process, various physiological and biochemical changes occur in plant cells, which may confer subsequent acquired chilling and freezing tolerance to plants. For example, during cold acclimation, plants accumulate compatible solutes such as sucrose, raffinose and proline [9-12]; membrane compositions and behaviors are changed [13-16]; and the biosynthesis pathways of secondary metabolites such as flavonoids are activated $[17,18]$.

The physiological and biochemical changes during plant cold acclimation result mainly from expression changes of cold-responsive (COR) genes. A large number of studies demonstrate that gene expression changes occur in a wide range of plant species in cold responses, and it is believed that differences in COR gene expressions contribute to differences in plant cold tolerance. For example, considerable differences in the members of COR genes were found in Solanum commersonii and Solanum tuberosum, which are closely related species that differ in cold acclimation abilities [19].

The expressions of COR genes in plant cold responses are under the control of some key transcription factors (TFs). The best characterized TFs involved in plant cold responses are a class of AP2/EFR TFs known as DREB/ CBF [20-23], which regulate COR gene expressions by binding to the DRE/CRT cis-elements in the promoter regions of $\mathrm{COR}$ genes. In Arabidopsis, there are three major CBFs - CBF1, CBF2 and CBF3 (also known as DREB1b, DREB1c, and DREB1a, respectively) [24]. Constitutive expression of CBF1 and CBF3 can enhance freezing tolerance in non-acclimated Arabidopsis [25]. Moreover, by studying the interactions with CBFs pathway, the roles of some cellular or environmental factors, such as calcium [26], light [27], and circadian rhythm
[28], in plant cold tolerance are revealed. Nonetheless, CBFs may not represent all TFs that regulate the expressions of COR genes and confer cold tolerance to plants. Although CBF over-expression increases the freezing tolerance of Arabidopsis, potato [29] and poplar [30], it does not increase the freezing tolerance of tomato [31] and rice [32]. Besides CBFs, some other TFs, such as ZAT12 and RAV1 [33,34], are also discovered to regulate the expressions of COR genes.

Given the importance of COR genes in plant cold tolerance, studying the cold responses at transcription level may be a key step to identify specific tolerance mechanisms of plants. During the last two decades, numerous studies were carried out to reveal the transcriptional regulatory network of plants in response to cold stress. However, most of the studies were performed with Arabidopsis and others were conducted with crops such as Brassica napus [35], rice [36], barley [37] and potato [19]. Some studies were performed with species adapted to arctic or alpine cold environments, such as Draba $[38,39]$ and Oxytropis [40], suggesting that plants may adapt to cold environments with different strategies and COR genes. However, due to lack of reference genome sequence, such studies are relatively few. Sequencing the genome of Coccomyxa subellipsoidea from the Antarctic suggested that gene losses and gains may contribute to low temperature adaptations [41], highlighting the importance of studying cold tolerance at whole genome or transcriptome level. Recently, the development of highthroughput deep-sequencing technologies makes it possible to study gene expressions at whole genome level without prior knowledge about reference genome sequence. In this study, we used Illumina deep-sequencing technology to study the transcriptome profiles of chilling-treated seedlings of C. bungeana.

C. bungeana is a Cruciferae species closely related to Arabidopsis. Our previous studies showed that the callus and suspension cells from $C$. bungeana were ready to endure freezing temperature $\left(-4^{\circ} \mathrm{C}\right)$ without cold acclimation $[3,6]$. The aim of this study is to examine what kinds of mechanisms contribute to the specific cold tolerance of $C$. bungeana. Our results showed a complicated regulatory network of C. bungeana responding to chilling stress. By comparative transcriptome analysis, a large number of common chilling responding processes, including a newly found karrikins responding process, were found in both $C$. bungeana and Arabidopsis. Furthermore, our results implied the differences between C. bungeana and Arabidopsis in cold acclimation and TF regulation networks. Importantly, our results suggested that protein phosphorylation and ubiquitination might serve as rapid and flexible mechanisms for cold tolerance regulations in C. bungeana. 
Table 1 Statistics of deep-sequencing

\begin{tabular}{llllll}
\hline Sample & Total reads & Total nucleotides $(\mathbf{n t})$ & Q20 percentage & N percentage & GC percentage \\
\hline Control & $41,499,576$ & $3,734,961,840$ & $95.44 \%$ & $0.01 \%$ & $47.48 \%$ \\
Cold-stressed & $40,009,694$ & $3,600,872,460$ & $95.92 \%$ & $0.00 \%$ & $47.55 \%$ \\
\hline
\end{tabular}

\section{Results and discussion}

Sequencing and de novo assembly of

\section{C. bungeana transcriptome}

Two cDNA libraries were generated with mRNA from control $\left(22^{\circ} \mathrm{C}\right)$ or 24 hours chilling-treated $\left(2^{\circ} \mathrm{C}\right)$ plants of $C$. bungeana and sequenced by Illumina deep-sequencing. 41,499,576 and 40,009,694 clean reads of 90 bp were generated from control and chilling-treated cDNA libraries, respectively (Table 1). De novo assembly was carried out by Trinity method [42] and final unigenes were obtained by TGICL clustering [43]. Overviews of the assembly results were shown in Table 2. The sequence reads were finally assembled into 54,870 nonredundant unigenes, spanning a total of $48.7 \mathrm{Mb}$ of sequence. All unigenes were longer than 200 bp. Mean length of final unigenes was 888 bp and N50 was 1401 bp. With the Trinity de novo assembly method, no $\mathrm{N}$ remained in the final unigenes. We also tried de novo assembly with SOAPdenovo program [44]. However, the assembly quality was worse than that of the Trinity method, with a mean length of 596 bp and N50 of $809 \mathrm{bp}$, and $13.9 \%$ of the final unigenes had at least one $\mathrm{N}$ remained (Table 3 ). The results were similar to the transcriptome assembly report of Aegilops variabilis [45], in which the assembly qualities of the Trinity method were superior to that of the SOAPdenovo method. Therefore, the assembly results from the Trinity method were used for all the following analysis.

Functional annotation of all the unigenes of $\mathrm{C}$. bungeana Functions of the unigenes were annotated based on sequence similarities to sequences in the three public

Table 2 Statistics of the assembly (unigene number and percentage) with the Trinity method

\begin{tabular}{llll}
\hline & Control & Cold-stressed & Combined \\
\hline 200-500nt & $21,064(45.52 \%)$ & $26,284(51.97 \%)$ & $25,233(45.99 \%)$ \\
500-1000nt & $11,421(24.68 \%)$ & $12,215(24.15 \%)$ & $12,746(23.23 \%)$ \\
1000-1500nt & $6,190(13.38 \%)$ & $5,811(11.49 \%)$ & $7,290(13.29 \%)$ \\
1500-2000nt & $3,651(7.89 \%)$ & $3,193(6.31 \%)$ & $4,458(8.12 \%)$ \\
> =2000nt & $3,946(8.53 \%)$ & $3,071(6.07 \%)$ & $5,143(9.37 \%)$ \\
N50 & 1,335 & 1,136 & 1,401 \\
Mean & 868 & 754 & 888 \\
All Unigene & 46,272 & 50,574 & 54,870 \\
Length of all & $40,180,147$ & $38,132,636$ & $48,708,039$ \\
Unigene (nt) & & & \\
\hline
\end{tabular}

databases (NR, Swissprot and KEGG). Among the 54,870 non-redundant unigenes, 43,524 (79.4\%) had at least one hit in BLASTX search with E-value $<=1 \mathrm{e}-5$ (Additional file 1). Functional classifications of GO terms of all unigenes were shown in Figure 1. In the category of biological process, the largest groups were "cellular process", "metabolic process" and "response to stimulus". In the category of molecular function, unigenes with "binding" and "catalytic" activities were the largest groups.

Expression analysis, differential expression genes (DEGs) identification and $\mathrm{qPCR}$ verifications

The expressions of unigenes were analyzed with DEGseq $\mathrm{R}$ package. Firstly, we tried to identify DEGs by applying screening thresholds of 2 fold changes and Benjamini $q$ value $<0.001$. We got 12,808 DEG candidates out of 52,753 expressed unigenes (Additional file 2). However, when we verified the expressions of the top 10 upregulated and down-regulated unigenes by RT-PCR and qPCR, only 3 of them were amplified and none of them showed up or down-regulated trends in chilling-treated seedlings (data not shown). In addition, we found that $80 \%$ and $90 \%$ of the top 200 up and down-regulated unigenes presented only in one sample's RNA-seq data, respectively. PCR amplification failures of the selected sequences suggested that such genes were most likely to be the artifacts of de novo assembly.

To identify DEGs accurately, we dropped off all unigenes with RPKM $<1$ in both sequencing libraries before DEGseq analysis. By this method, 8,055 DEGs (25.7\%; 3,484 up-regulated, 4,571 down-regulated) out of 31,295

Table 3 Statistics of the assembly (unigene number and percentage) with the SOAPdenovo software

\begin{tabular}{llll}
\hline & Control & Cold-stressed & Combined \\
\hline 100-500nt & $48701(72.6 \%)$ & $57007(77.46 \%)$ & $39728(62.99 \%)$ \\
500-1000nt & $12066(17.99 \%)$ & $11880(16.14 \%)$ & $14121(22.39 \%)$ \\
$1000-1500 \mathrm{nt}$ & $3539(5.28 \%)$ & $2987(4.06 \%)$ & $4897(7.76 \%)$ \\
$1500-2000 \mathrm{nt}$ & $1479(2.2 \%)$ & $1054(1.43 \%)$ & $2220(3.52 \%)$ \\
$>=2000 \mathrm{nt}$ & $1296(1.93 \%)$ & $663(0.9 \%)$ & $2108(3.34 \%)$ \\
N50 & 634 & 502 & 809 \\
Mean & 474 & 413 & 596 \\
All Unigene & 67,081 & 73,591 & 63,074 \\
Length of all & $31,789,071$ & $30,382,210$ & $37,575,882$ \\
Unigene (nt) & & & \\
\hline
\end{tabular}




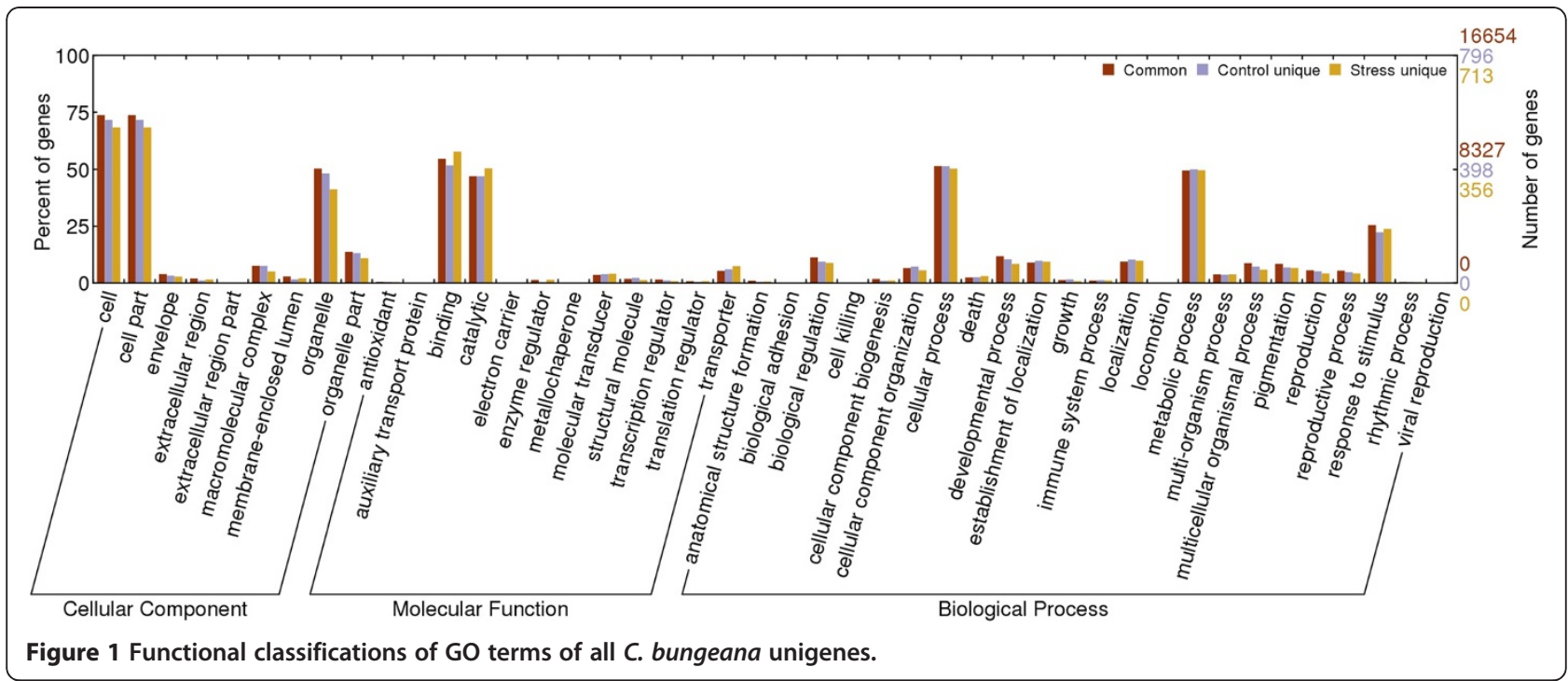

unigenes with minimal 1.0 RPKM in both cDNA samples were identified (Additional file 3). The top 50 most up- or down-regulated unigenes were listed in Table 4 and Table 5, respectively. A number of genes involved in cold or other stresses showed up in the top 50 upregulated list, such as putative orthologous genes (POGs) of COR15A, ABR1, pectin methylesterase inhibitor gene, MAPKKK13, heat shock transcription factor $A 1 E$ and LTI65 genes. A putative ortholog of Arabidopsis COR15A, which encodes a cryoprotective protein located to the chloroplast stroma [46], was identified as the most up-regulated unigene in C. bungeana.

The top 20 up-regulated DEGs were selected to verify the expressions of the indentified DEGs by qPCR analysis. To get more reliable quantification results, we performed an experiment in advance to screen reference genes for qPCR (see Methods for details), and the relative expression levels of unigenes were normalized to 3 stable expressed reference genes. The results showed that 18 of the top 20 up-regulated DEGs (90\%) were verified to be up-regulated by qPCR analysis, although their fold changes differed from that of RNA-seq (Figure 2). Except for CBT7920 and CBT22908, the expressions of all other tested unigenes showed at least 3-fold increases after 24-hour chilling treatment. The most up-regulated unigene were POGs encoded a plant invertase/pectin methylesterase inhibitor superfamily protein (CBT4773, 552 folds). COR15A (CBT13817, 318 folds) was also induced remarkably by chilling.

High throughput deep-sequencing is a powerful tool for DEGs screening, especially for species without available genomic information $[45,47,48]$. However, since Illumina sequencing is highly sensitive to templates presented in DNA samples, some traced transcripts or contaminants can be sequenced in one sample but not in other samples. This will have huge effects on the results of de novo assembly and increase false positive rate in DEGs identification. One strategy to reduce the false positive results is to set up biological repeats for sequencing and increase sequencing depth, but it will greatly increase the experimental costs. In this study, by simply applying an additional threshold (RPKM $>=1$ ) for DEGs screening without increasing costs, we got a high quality (confirmed by qPCR) list of chilling regulated DEGs.

\section{GO network analysis of up-regulated DEGs of C. bungeana in response to chilling stress and comparison with Arabidopsis}

Since both C. bungeana and Arabidopsis are Cruciferae species, it is more reliable to use the well-established GO and KEGG annotation systems of Arabidopsis to analyze the functions of $C$. bungeana DEGs. GO term and KEGG pathway enrichment analysis of DEGs were conducted with BiNGO [49], a Cytoscape plugin assessing overrepresentation of ontologies in biological networks, using the list of all unigenes with a minimal RPKM of 1 in both sequencing libraries as a reference set. To compare the chilling responding network of $C$. bungeana with Arabidopsis, the networks of chillingregulated DEGs of Arabidopsis were constructed using previously published RNA-seq and microarray data (referred to ATH-SR and ATH-MA, respectively; see Methods for details).

In chilling up-regulated DEGs of C. bungeana and Arabidopsis, two similar clusters in the networks of GO biological process, "regulation processes" and "stimulus responses", were found among all three networks/datasets (Figure 3). In BiNGO constructed networks, most biological information can be inferred from end nodes and their relations with their source nodes such as gene 
Table 4 Top 50 up-regulated unigenes of $C$. bungeana by chilling stress. The homologs of Arabidopsis genes were presented for functional description of unigenes

\begin{tabular}{llll}
\hline Unigene & $\begin{array}{l}\text { log2 } \\
\text { (Fold change) }\end{array}$ & AGI & Functional description \\
\hline CBT13817 & 7.47 & AT2G42540 & cold-regulated 15a (COR15A)
\end{tabular}

$\begin{array}{llll}\text { CBT52238 } & 6.67 & - & - \\ \text { CBT6902 } & 6.32 & \text { AT5G64750 } & \text { ABA REPRESSOR1 (ABR1) }\end{array}$

CBT7920 6.13

$\begin{array}{ccll}\text { CBT13614 } & 6.10 & \text { AT5G63450 } & \begin{array}{l}\text { cytochrome P450, family 94, } \\ \text { subfamily B, polypeptide 1 } \\ \text { (CYP94B1) }\end{array} \\ \text { CBT4773 } & 6.10 & \text { AT5G62360 } & \begin{array}{l}\text { Plant invertase/pectin } \\ \text { methylesterase inhibitor } \\ \text { superfamily protein }\end{array} \\ \text { CBT52823 } & 6.06 & - & - \\ \text { CBT22908 } & 5.91 & \text { AT1G22810 } & \begin{array}{l}\text { Integrase-type DNA-binding } \\ \text { superfamily protein }\end{array} \\ \text { CBT13319 } & 5.51 & \text { AT1G07150 } & \begin{array}{l}\text { mitogen-activated protein } \\ \text { kinase kinase kinase 13 } \\ \text { (MAPKKK13) }\end{array} \\ & & & - \\ \text { CBT47699 } & 5.46 & - & \text { - } \\ \text { CBT15934 } & 5.40 & \text { AT2G38240 } & \begin{array}{l}\text { 2-oxoglutarate (2OG) and } \\ \text { Fe(II)-dependent oxygenase } \\ \text { superfamily protein }\end{array} \\ & & & \end{array}$

$-$

AT5G65140 Haloacid dehalogenase-like hydrolase (HAD) superfamily protein

$$
\begin{array}{ll}
\text { AT5G17460 } & \text { unknown protein } \\
\text { AT1G19670 chlorophyllase 1 (CLH1) } & \text { AT5G63450 } \\
\text { cytochrome P450, family 94, } \\
\begin{array}{l}
\text { subfamily B, polypeptide 1 } \\
\text { (CYP94B1) }
\end{array}
\end{array}
$$

$\begin{array}{ll}- & - \\ \text { AT3G02990 } & \begin{array}{l}\text { heat shock transcription } \\ \text { factor A1E (HSFA1E) }\end{array} \\ \text { AT5G45860 } & \text { PYR1-like 11 (PYL11) } \\ \text { AT4G34131 } & \text { UDP-glucosyl transferase } \\ & \text { 73B3 (UGT73B3) } \\ \text { AT4G01870 } & \text { tolB protein-related } \\ \text { AT1G11925 } & \begin{array}{l}\text { Stigma-specific Stig1 family } \\ \text { protein }\end{array} \\ \text { AT1G02400 } & \begin{array}{l}\text { gibberellin 2-oxidase 6 } \\ \text { (GA2OX6) }\end{array} \\ \text { AT3G06490 } & \begin{array}{l}\text { myb domain protein 108 } \\ \text { (MYB108) }\end{array} \\ \text { AT5G38780 } & \begin{array}{l}\text { S-adenosyl-L-methionine- } \\ \text { dependent methyltransferases } \\ \text { superfamily protein }\end{array}\end{array}$
superfamily protein

\begin{tabular}{|c|c|c|c|}
\hline CBT6326 & 4.79 & AT3G04010 & $\begin{array}{l}\text { O-Glycosyl hydrolases family } \\
17 \text { protein }\end{array}$ \\
\hline CBT17469 & 4.79 & AT4G14690 & $\begin{array}{l}\text { EARLY LIGHT-INDUCIBLE } \\
\text { PROTEIN } 2 \text { (ELIP2) }\end{array}$ \\
\hline CBT47754 & 4.76 & AT1G25220 & $\begin{array}{l}\text { anthranilate synthase beta } \\
\text { subunit } 1 \text { (ASB1) }\end{array}$ \\
\hline CBT1612 & 4.74 & AT5G52300 & $\begin{array}{l}\text { LOW-TEMPERATURE-INDUCED } \\
65 \text { (LTI65) }\end{array}$ \\
\hline CBT29537 & 4.73 & AT2G33710 & $\begin{array}{l}\text { Integrase-type DNA-binding } \\
\text { superfamily protein }\end{array}$ \\
\hline CBT3801 & 4.68 & AT1G57990 & $\begin{array}{l}\text { purine permease } 18 \\
\text { (PUP18) }\end{array}$ \\
\hline CBT17111 & 4.64 & AT5G67600 & unknown protein \\
\hline CBT8371 & 4.61 & AT2G46950 & $\begin{array}{l}\text { cytochrome P450, family 709, } \\
\text { subfamily B, polypeptide } 2 \\
\text { (CYP709B2) }\end{array}$ \\
\hline CBT21020 & 4.61 & - & - \\
\hline CBT28985 & 4.59 & AT1G65690 & $\begin{array}{l}\text { Late embryogenesis abundant } \\
\text { (LEA) hydroxyproline-rich } \\
\text { glycoprotein family }\end{array}$ \\
\hline CBT336 & 4.59 & AT3G24900 & $\begin{array}{l}\text { receptor like protein } 39 \\
\text { (RLP39) }\end{array}$ \\
\hline CBT845 & 4.57 & AT2G34930 & $\begin{array}{l}\text { disease resistance family } \\
\text { protein / LRR family protein }\end{array}$ \\
\hline CBT18111 & 4.55 & AT1G05530 & $\begin{array}{l}\text { UDP-glucosyl transferase } \\
\text { 75B2 (UGT75B2) }\end{array}$ \\
\hline CBT45699 & 4.55 & - & - \\
\hline CBT9147 & 4.52 & - & - \\
\hline CBT37125 & 4.51 & - & - \\
\hline CBT47516 & 4.50 & AT2G43840 & $\begin{array}{l}\text { UDP-glycosyltransferase } 74 \text { F1 } \\
\text { (UGT74F1) }\end{array}$ \\
\hline CBT7419 & 4.50 & AT1G64380 & $\begin{array}{l}\text { Integrase-type DNA-binding } \\
\text { superfamily protein }\end{array}$ \\
\hline CBT51514 & 4.47 & - & - \\
\hline CBT2368 & 4.46 & - & - \\
\hline CBT7125 & 4.44 & AT1G26390 & $\begin{array}{l}\text { FAD-binding Berberine family } \\
\text { protein }\end{array}$ \\
\hline
\end{tabular}

Table 4 Top 50 up-regulated unigenes of $C$. bungeana by chilling stress. The homologs of Arabidopsis genes were presented for functional description of unigenes (Continued)

numbers (node sizes) and $p$ values (node colors) [49]. In "regulation processes" cluster of all three networks, genes involved in "regulation of transcription, DNAdependent" accounted for the enrichments of all other nodes in this network branch since the end node was almost the same size and color as its source nodes, suggesting that transcriptional regulations might have common contributions in plants responding to chilling stress. In the cluster of "stimulus responses", the network patterns showed that cellular responses to a wide range of stresses were aroused by chilling stress in both C. bungeana and Arabidopsis, which were probably due 
Table 5 Top 50 down-regulated unigenes of $C$. bungeana by chilling stress. The homologs of Arabidopsis genes were presented for functional description of unigenes

\begin{tabular}{|c|c|c|c|}
\hline Unigene & $\begin{array}{l}\text { log2 } \\
\text { (fold change) }\end{array}$ & AGI & Computational_description \\
\hline CBT30334 & -3.99 & AT2G14660.1 & unknown protein \\
\hline CBT13943 & -3.76 & - & - \\
\hline CBT2874 & -3.74 & - & - \\
\hline CBT48038 & -3.46 & - & - \\
\hline CBT3212 & -3.44 & - & - \\
\hline CBT34638 & -3.28 & - & - \\
\hline CBT8991 & -3.27 & - & - \\
\hline CBT19662 & -3.25 & AT3G06145.1 & unknown protein \\
\hline CBT30596 & -3.21 & AT5G06950.4 & AHBP-1B \\
\hline CBT22861 & -3.04 & - & - \\
\hline CBT7674 & -3.02 & - & - \\
\hline CBT7734 & -2.98 & AT5G62280.1 & $\begin{array}{l}\text { Protein of unknown function } \\
\text { (DUF1442) }\end{array}$ \\
\hline CBT3347 & -2.98 & - & - \\
\hline CBT31902 & -2.94 & - & - \\
\hline CBT17505 & -2.91 & AT3G06740.1 & $\begin{array}{l}\text { GATA transcription factor } 15 \\
\text { (GATA15) }\end{array}$ \\
\hline CBT24596 & -2.90 & - & - \\
\hline CBT15245 & -2.90 & - & - \\
\hline CBT27066 & -2.90 & - & - \\
\hline CBT2813 & -2.89 & AT4G20270.1 & $\begin{array}{l}\text { BARELY ANY MERISTEM } 3 \\
\text { (BAM3) }\end{array}$ \\
\hline CВT39819 & -2.88 & - & - \\
\hline CBT2069 & -2.87 & - & - \\
\hline CBT26600 & -2.85 & AT3G17668.1 & $\begin{array}{l}\text { ENHANCER OF ATNSI } \\
\text { ACTIVITY (ENA) }\end{array}$ \\
\hline CBT7789 & -2.83 & - & - \\
\hline CBT7793 & -2.83 & AT3G48970.1 & $\begin{array}{l}\text { Heavy metal transport/ } \\
\text { detoxification superfamily } \\
\text { protein }\end{array}$ \\
\hline CBT38584 & -2.82 & AT3G60910.1 & $\begin{array}{l}\text { S-adenosyl-L-methionine- } \\
\text { dependent } \\
\text { methyltransferases } \\
\text { superfamily protein }\end{array}$ \\
\hline CBT5244 & -2.81 & AT3G52905.1 & $\begin{array}{l}\text { Polynucleotidyl transferase, } \\
\text { ribonuclease H-like } \\
\text { superfamily protein }\end{array}$ \\
\hline CBT26673 & -2.80 & - & - \\
\hline CBT27159 & -2.78 & AT5G55540.1 & TORNADO 1 (TRN1) \\
\hline CBT15242 & -2.75 & - & - \\
\hline CBT13738 & -2.73 & AT3G54560.1 & histone H2A 11 (HTA11) \\
\hline CBT38583 & -2.70 & - & - \\
\hline CBT31492 & -2.69 & - & - \\
\hline CBT38499 & -2.69 & - & - \\
\hline CBT29663 & -2.68 & - & - \\
\hline CBT6741 & -2.68 & - & - \\
\hline
\end{tabular}

Table 5 Top 50 down-regulated unigenes of $C$. bungeana by chilling stress. The homologs of Arabidopsis genes were presented for functional description of unigenes (Continued)

\begin{tabular}{|c|c|c|c|}
\hline CBT30636 & -2.67 & - & - \\
\hline CBT26681 & -2.66 & - & - \\
\hline CBT23205 & -2.65 & AT5G54550.1 & $\begin{array}{l}\text { Protein of unknown function } \\
\text { (DUF295) }\end{array}$ \\
\hline CBT4916 & -2.64 & AT5G26860.1 & lon protease 1 (LON1) \\
\hline CBT2774 & -2.63 & - & - \\
\hline CBT40023 & -2.63 & - & - \\
\hline CBT3096 & -2.62 & AT1G80080.1 & TOO MANY MOUTHS (TMM) \\
\hline СВТ39489 & -2.62 & - & - \\
\hline СВT30184 & -2.62 & - & - \\
\hline CBT3289 & -2.62 & AT1G03270.1 & $\begin{array}{l}\text { CBS domain-containing } \\
\text { protein with a domain of } \\
\text { unknown function (DUF21) }\end{array}$ \\
\hline СВT30641 & -2.61 & - & - \\
\hline CBT34154 & -2.61 & - & - \\
\hline CBT34041 & -2.60 & - & - \\
\hline СВT39400 & -2.59 & AT3G01690.1 & $\begin{array}{l}\text { alpha/beta-Hydrolases } \\
\text { superfamily protein }\end{array}$ \\
\hline CBT23404 & -2.59 & - & - \\
\hline
\end{tabular}

to the cross-tolerance mechanisms of plants. The cluster of "metabolism processes" comprised much more overrepresentative terms in the network of $C$. bungeana than that of Arabidopsis. "Flavonoid biosynthetic process" was the only over-representative term of this cluster presented in both C. bungeana and Arabidopsis (ATH-SR).

Twelve biological processes (end nodes in the networks) were found to be common in both $C$. bungeana and Arabidopsis (ATH-SR or ATH-MA), and ten of them were related to stimulus responses (Table 6). Genes "response to cold" were over-representative in all three networks, suggesting that our chilling stress treatments were efficient. However, the genes involved in "cold acclimation" did not over-represent in C. bungeana as did in Arabidopsis (Figure 3), indicating that cold acclimation mechanisms were not activated by chilling in C. bungeana. The results imply that $C$. bungeana may not have a cold acclimated mechanism or may have cold acclimated mechanisms different from that of Arabidopsis. For plants from temperate regions, cold acclimation is critical for them to tolerate freezing temperatures [8]. However, since cold acclimation requires a relatively long period of time to get freezing tolerance, such mechanisms may not be suitable for plants like C. bungeana in harsh environments. More rapid and efficient mechanisms are needed for such plants.

Besides abscisic acid [50] and chitin responses [51], which were known to be involved in cold tolerance of 


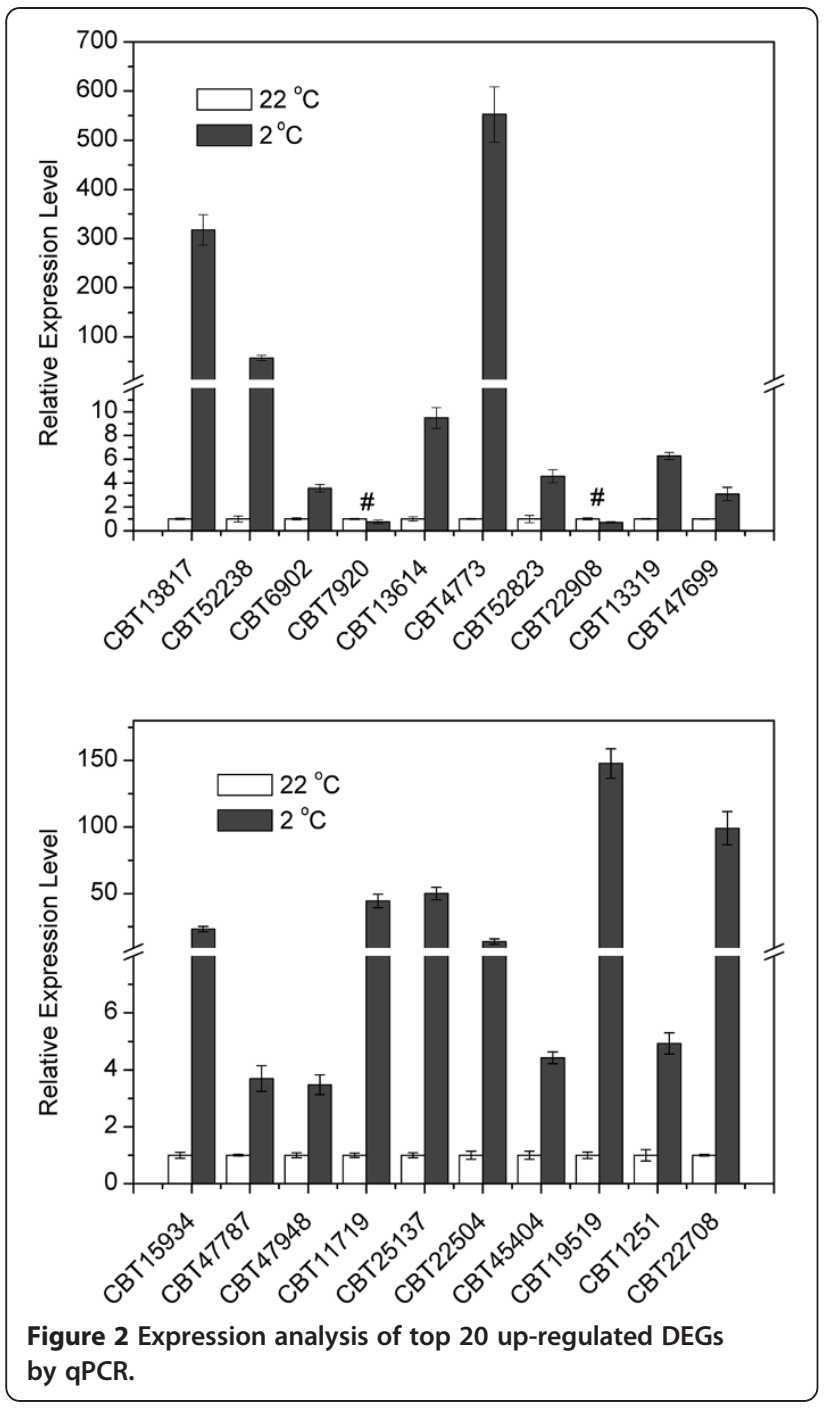

plants, the biological process "response to karrikin" was found to be a common response to chilling stress in both C. bungeana and Arabidopsis. To our knowledge, no previous study reported the involvement of karrikins in cold tolerance of plants. Karrikins are a new group of plant growth regulators discovered in smoke that can stimulate seed germination [52]. The biological and molecular functions of karrikins are largely unknown at present. Our results suggested that karrikins might play important roles in chilling tolerance of $C$. bungeana and Arabidopsis.

Nineteen biological processes were over-represented in chilling-treated $C$. bungeana but not in Arabidopsis. Nonetheless, it did not mean that such processes were specific to chilling responses of $C$. bungeana since most of them, such as salicylic acid [53,54], jasmonic acid [54], and immune response [55], were reported to be involved in chilling response of Arabidopsis or other plants. However, two processes, "protein phosphorylation" and "protein autoubiquitination", should be emphasized. Post-translational modifications of pre-existing proteins are believed to be a rapid pathway to get tolerance in plant responses to chilling stress and have important roles in plant cold acclimation [8]. In alfafa, low temperature lead to rapid inhibition of PP2A activity, and in turn lead to phosphorylation of proteins involved in cold tolerance acquisitions [56,57]. Transcriptional activation of genes of several kinase families were also found under low temperature stress, such as MAP kinase family genes MKK2 [58], OsMEK1 and OsMAP1 [59], CDPK family genes OsCDPK7 [60,61], OsCDPK13 [62] and PaCDPK1 [63], and CIPK family genes CIPK3 [64] and CIPK7 [65]. Although many studies reported that certain protein kinases were activated and their transcriptional expression increased in response to cold stress, few studies reported that the expressions of protein kinases as a whole increased at transcriptome level. In our study, a large number of genes whose products were involved in protein phosphorylation were overrepresented in chilling up-regulated DEGs in C. bungeana. Given the habitats of C. bungeana, in which the daytime temperatures fluctuate frequently and during almost the whole plant growing seasons, our results suggest that protein phosphorylation may be an important mechanism for rapid and flexible regulation of cold tolerance of C. bungeana.

Protein autoubiquitination may play similar roles as protein phosphorylation. In Arabidopsis, ubiquitination of ICE1 by HOS1 which leads to ICE1 degradation is vital for the activation of CBF pathways [66]. In this study, eight chilling up-regulated unigenes of C. bungeana were associated with protein ubiquitination, six of which might be involved directly in protein ubiquitination (Table 7). However, POGs of HOS1 was not on the list. Therefore, the roles of protein ubiquitination in chilling responses of $C$. bungeana need further investigations.

Comparison of the molecular function networks of chilling up-regulated DEGs showed that only one term/ node, "sequence-specific DNA binding transcription factor activity", was in common in both C. bungeana and Arabidopsis (Figure 4, Table 6). It was consistent with the over-representative term of "regulation of transcription, DNA-dependent" in network of biological process. However, only a small amount of TF POGs of the three experiments were overlapped (Figure 5A), including ZAT12/RHL41, COL1, TOC1 and RAP2.7 orthologs (Table 8) which were reported to be involved in plant cold responses $[33,34,67,68]$. Surprisingly, none of the CBFs (CBF1/DREB1b, CBF2/DREB1c and CBF3/ $D R E F 1 a$ ) was on the list of overlapped TF genes though $C B F 2$ and $C B F 3$ were chilling up-regulated in Arabidopsis as was shown by both ATH-SR and ATH-AR data 


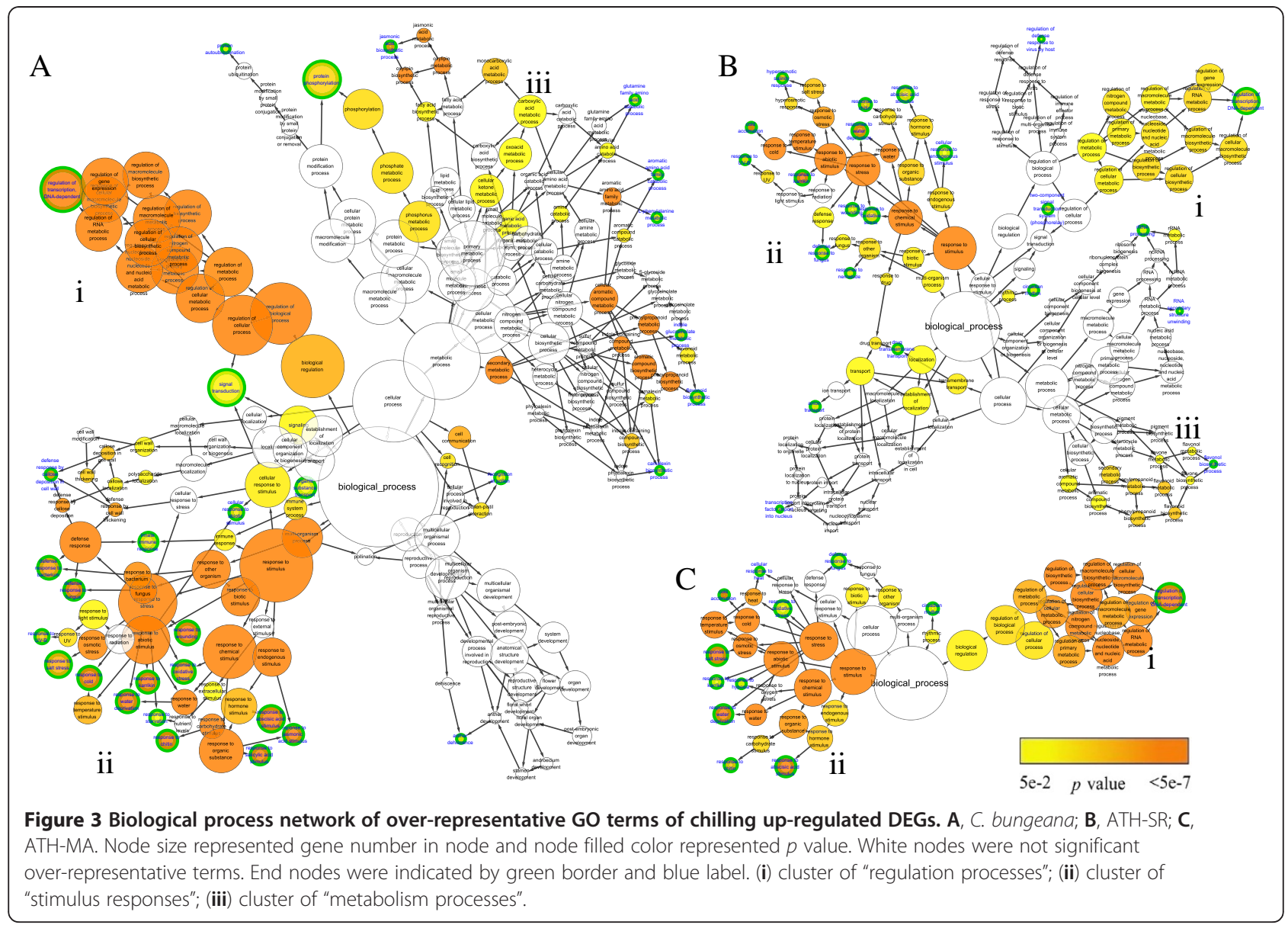

Table 6 Over-representative GO terms* in chilling-treated C. bungeana and Arabidopsis

\begin{tabular}{|c|c|c|}
\hline GO ID & GO functional description & Corrected $p$-value \\
\hline \multicolumn{3}{|c|}{ Biological process: } \\
\hline 80167 & response to karrikin & $1.59 \mathrm{E}-24$ \\
\hline 9611 & response to wounding & $9.61 \mathrm{E}-23$ \\
\hline 10200 & response to chitin & $1.61 \mathrm{E}-19$ \\
\hline 6355 & $\begin{array}{l}\text { regulation of transcription, } \\
\text { DNA-dependent }\end{array}$ & $3.72 \mathrm{E}-16$ \\
\hline 9414 & response to water deprivation & 1.89E-09 \\
\hline 9737 & response to abscisic acid stimulus & $2.36 \mathrm{E}-08$ \\
\hline 9409 & response to cold & $1.10 \mathrm{E}-07$ \\
\hline 50832 & defense response to fungus & $1.20 \mathrm{E}-07$ \\
\hline 6979 & response to oxidative stress & $8.15 E-06$ \\
\hline 9651 & response to salt stress & $2.92 \mathrm{E}-05$ \\
\hline 10224 & response to UV-B & $4.68 \mathrm{E}-04$ \\
\hline 9813 & flavonoid biosynthetic process & 7.10E-03 \\
\hline \multicolumn{3}{|c|}{ Molecular function: } \\
\hline 3700 & $\begin{array}{l}\text { sequence-specific DNA binding } \\
\text { transcription factor activity }\end{array}$ & $1.11 \mathrm{E}-23$ \\
\hline
\end{tabular}

* Only GO terms of the end nodes in the network were presented.
(Additional file 4). In fact, no ortholog of Arabidopsis $C B F 1$ or $C B F 2$ was found in the transcriptome of $C$. bungeana, while there were orthologs of $C B F 3$ and CBF4 (data not shown). The results suggest that the transcriptional activation mechanism of $C$. bungeana differs greatly from that of Arabidopsis in chilling responses although they share some common mechanisms. Given the important roles of CBFs in plant cold acclimation, lack of $C B F$ orthologs suggests that cold acclimation mechanisms may be weak in or absent from C. bungeana, consisting with the finding that genes involved in cold acclimation was not enriched in chilling up-regulated DEGs of C. bungeana. Classification results showed that MYB, AP2/ERF, WRKY and NAC family members represent the most abundant TFs in chilling up-regulated DEGs of C. bungeana (Figure 5B). The data are insightful for further investigation of specific tolerance mechanisms of $C$. bungeana.

Ten terms/nodes in the network of C. bungeana were not in the networks of Arabidopsis (Figure 4, Table 9). Again, the over-representation of "protein serine/threonine kinase activity" was overlapped with "protein phosphorylation" in the network of biological process. The most abundant protein kinases in chilling up-regulated 
Table 7 Chilling up-regulated unigenes annotated with ubiquitination function

\begin{tabular}{|c|c|c|}
\hline Unigene & AGI model & Functional description \\
\hline CBT4839 & AT5G57740.1 & $\begin{array}{l}\text { ubiquitin ligase, XB3 ortholog } 2 \text { in } \\
\text { Arabidopsis thaliana (XBAT32) }\end{array}$ \\
\hline CBT21694 & AT5G57740.1 & $\begin{array}{l}\text { ubiquitin ligase, XB3 ortholog } 2 \text { in } \\
\text { Arabidopsis thaliana (XBAT32) }\end{array}$ \\
\hline CBT25162 & AT3G52450.1 & $\begin{array}{l}\text { U-box domain E3 ubiquitin ligase } \\
\text { protein, plant U-box } 22 \text { (PUB22) }\end{array}$ \\
\hline CBT24438 & AT2G35930.1 & $\begin{array}{l}\text { U-box domain E3 ubiquitin ligase } \\
\text { protein, plant U-box } 23 \text { (PUB23) }\end{array}$ \\
\hline CBT12523 & AT3G11840.1 & $\begin{array}{l}\text { U-box domain E3 ubiquitin ligase } \\
\text { protein, plant U-box } 24 \text { (PUB24) }\end{array}$ \\
\hline CBT9995 & AT3G12630.1 & $\begin{array}{l}\text { A20/AN1-like zinc finger family } \\
\text { protein }\end{array}$ \\
\hline CBT15631 & AT3G46620.1 & $\begin{array}{l}\text { zinc finger (C3HC4-type RING finger) } \\
\text { family protein }\end{array}$ \\
\hline
\end{tabular}

DEGs encoded cysteine-rich receptor-like protein kinases (CRK), whose roles in plant cold responses were largely unknown (Figure 6, Additional file 5). Genes for leucine-rich receptor-like protein kinases (LRR RLK) ranked the second. A small number of POGs of CDPKs, CIPKs, MPKs, MKKs and MKKKs, some of which have been reported to be involved in plant cold responses [58-65], were found in chilling up-regulated DEGs of C. bungeana.
KEGG pathway analysis of up-regulated DEGs of C. bungeana in response to chilling stress and comparison with Arabidopsis

KEGG pathway network analysis showed that "Biosynthesis of Other Secondary Metabolites" and "Environmental Adaptation" were enriched in chilling up-regulated DEGs of C. bungeana (Figure 7). The overrepresentation of "Biosynthesis of Other Secondary Metabolites" was due to biosynthesis of three kinds of secondary metabolites: flavonoids, glucosinolates and phenylpropanoids; and the over-presentation of "Environmental Adaptation" was due to enrichment of genes involved in "plant-pathogen interaction" and "circadian rhythm" regulation. Besides, genes involved in alpha linolenic acid metabolism were also enriched. The phenylalanine/tyrosine/tryptophan biosynthesis pathway was overlapped with phenylpropanoid biosynthesis. In Arabidopsis, genes involved in flavonoids biosynthesis and circadian rhythm pathways were also enriched in chilling up-regulated DEGs.

All over-represented pathways in C. bungeana, regardless of whether they were enriched in Arabidopsis, had proved to be important in plant cold tolerance. For instance, circadian rhythm regulates the expression of CBFs [28,69], the core identified TFs that involved in plant cold tolerance. As another example, under chilling stress, plants preferentially accumulate polyunsaturated

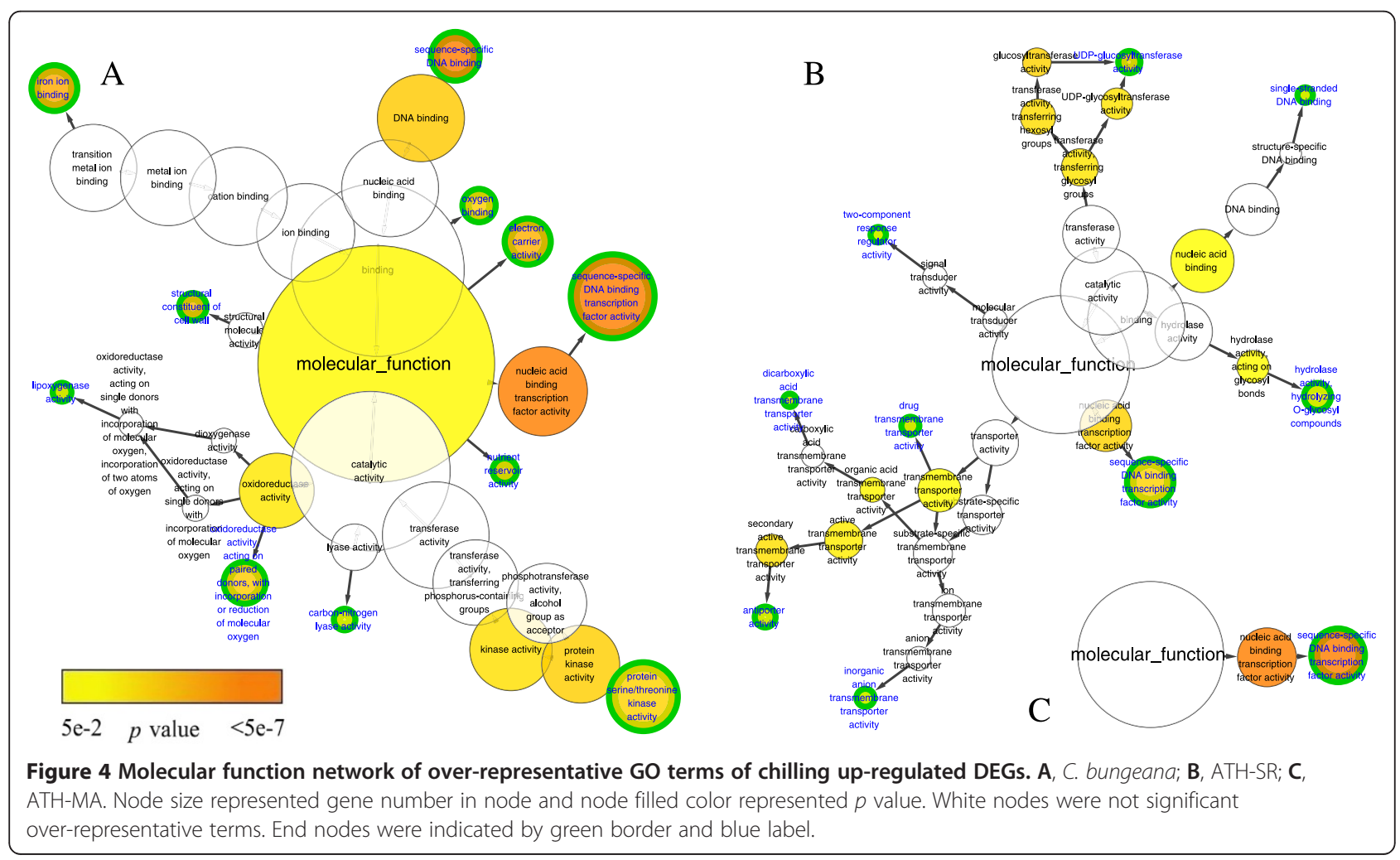



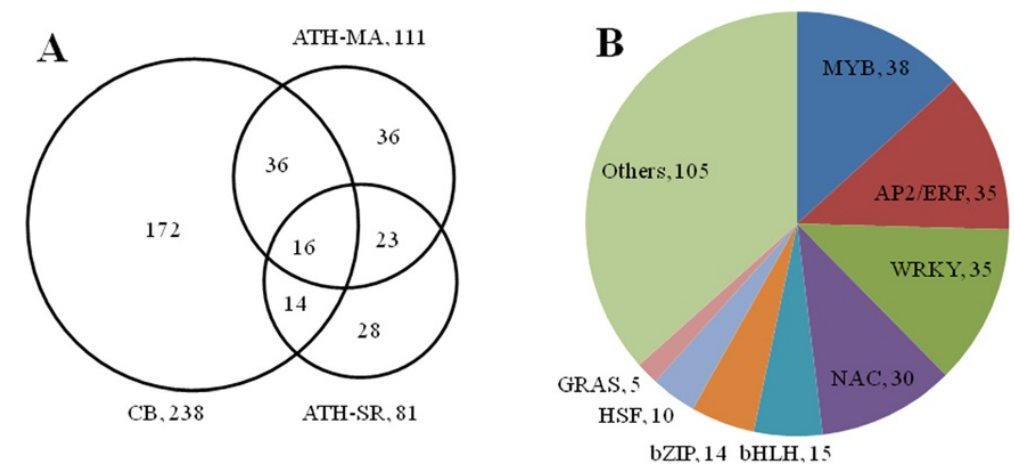

Figure 5 Analysis of chilling up-regulated TFs. A. Venn diagram of chilling up-regulated TFs in C. bungeana and Arabidopsis. B. Classification of chilling up-regulated transcription factors of C. bungeana by family.

Table 8 Chilling up-regulated TFs overlapped in C. bungeana and Arabidopsis

\begin{tabular}{|c|c|c|}
\hline Locus Id & All gene symbols & Description \\
\hline AT5G15850 & COL1 & $\begin{array}{l}\text { Homologous to the flowering-time } \\
\text { gene CONSTANS. }\end{array}$ \\
\hline AT2G40140 & CZF1; SZF2; ZFAR1 & CZF1 \\
\hline AT5G05410 & DREB2A & $\begin{array}{l}\text { Encodes a transcription factor that } \\
\text { specifically binds to DRE/CRT cis } \\
\text { elements (responsive to drought } \\
\text { and low-temperature stress) }\end{array}$ \\
\hline AT3G02990 & HSFA1E & $\begin{array}{l}\text { Member of Heat Stress Transcription } \\
\text { Factor (Hsf) family }\end{array}$ \\
\hline AT2G28550 & RAP2.7 & Related to AP2.7 (RAP2.7) \\
\hline AT5G59820 & RHL41; ZAT12 & $\begin{array}{l}\text { Encodes a zinc finger protein } \\
\text { involved in high light and cold } \\
\text { acclimation }\end{array}$ \\
\hline AT5G17300 & RVE1 & $\begin{array}{l}\text { Myb-like transcription factor that } \\
\text { regulates hypocotyl growth by } \\
\text { regulating free auxin levels in a } \\
\text { time-of-day specific manner. }\end{array}$ \\
\hline AT4G18390 & $\begin{array}{l}\text { TEOSINTE } \\
\text { BRANCHED 1; TCP2 }\end{array}$ & $\begin{array}{l}\text { TEOSINTE BRANCHED 1, cycloidea } \\
\text { and PCF transcription factor } 2 \text { (TCP2) }\end{array}$ \\
\hline AT5G61380 & TOC1;PRR1 & $\begin{array}{l}\text { Pseudo response regulator involved } \\
\text { in the generation of circadian } \\
\text { rhythms. }\end{array}$ \\
\hline AT2G47260 & WRKY23 & $\begin{array}{l}\text { Encodes a member of WRKY } \\
\text { Transcription Factor }\end{array}$ \\
\hline AT2G38470 & WRKY33 & $\begin{array}{l}\text { Member of the plant WRKY } \\
\text { transcription factor family }\end{array}$ \\
\hline AT1G80840 & WRKY40 & $\begin{array}{l}\text { Pathogen-induced transcription } \\
\text { factor }\end{array}$ \\
\hline AT5G54470 & & $\begin{array}{l}\text { B-box type zinc finger family } \\
\text { protein }\end{array}$ \\
\hline AT5G58620 & & $\begin{array}{l}\text { Zinc finger (CCCH-type) family } \\
\text { protein }\end{array}$ \\
\hline AT1G43860 & & $\begin{array}{l}\text { Sequence-specific DNA binding } \\
\text { transcription factors }\end{array}$ \\
\hline AT2G47890 & & $\begin{array}{l}\text { B-box type zinc finger protein with } \\
\text { CCT domain }\end{array}$ \\
\hline
\end{tabular}

fatty acids such as linoleic and linolenic fatty acids [70-72], and genetically increasing of unsaturated fatty acids or lipids could enhance cold tolerance of transgenic plants, probably by maintaining membrane fluidity under cold stress [73,74]. Our previous findings indicated that cold tolerance of $C$. bungeana was correlated with changes in membrane lipids and membrane-associated enzymes [3]. Under chilling treatment, the proportion of unsaturated fatty acid in the plasma membrane increased significantly in callus of C. bungeana [75]. Paralleling to these results, KEGG analysis in this study showed that unigenes involved in "alpha-Linolenic acid metabolism" were enriched significantly in chilling up-regulated DEGs, suggesting that lipid metabolism, especially linolenic acid metabolism, might play a role in chilling tolerance of C. bungeana.

\section{GO network analysis of down-regulated DEGs of C. bungeana in response to chilling stress and comparison with Arabidopsis}

In chilling stress down-regulated DEGs of both C. bungeana and Arabidopsis, there were several overrepresented terms in every biological process networks (Figure 8). However, no over-represented term was in common in C. bungeana and Arabidopsis. Furthermore, none of the over-represented term was the same between two networks of Arabidopsis, although both of them were related to chilling stressed downregulated DEGs. Similar results were also found in the networks of molecular function (Figure 9). The huge discrepancy among the networks implied that the gene members of chilling stress down-regulated DEGs were highly variable, which might be affected by some subtle experimental details other than chilling temperatures only. It was hard to deduce an unbiased mechanism from their networks analysis. Therefore, no further analysis was performed for the downregulated DEGs. 
Table 9 Over-representative GO terms* in chilling stressed $C$. bungeana but not in Arabidopsis

\begin{tabular}{|c|c|c|}
\hline GO ID & Description & Corrected $p$-value \\
\hline \multicolumn{3}{|c|}{ Biological process: } \\
\hline \multicolumn{3}{|c|}{ Stimulus responses related: } \\
\hline 9751 & response to salicylic acid stimulus & 7.70E-10 \\
\hline 9753 & response to jasmonic acid stimulus & $6.36 \mathrm{E}-09$ \\
\hline 52544 & $\begin{array}{l}\text { defense response by callose } \\
\text { deposition in cell wall }\end{array}$ & 3.95E-06 \\
\hline 42742 & defense response to bacterium & 1.09E-05 \\
\hline 45087 & innate immune response & 5.27E-03 \\
\hline 71214 & cellular response to abiotic stimulus & $5.41 \mathrm{E}-03$ \\
\hline 42594 & response to starvation & $2.31 \mathrm{E}-02$ \\
\hline \multicolumn{3}{|c|}{ Metabolism processes: } \\
\hline 9695 & jasmonic acid biosynthetic process & 3.95E-06 \\
\hline 42343 & indole glucosinolate metabolic process & $6.93 \mathrm{E}-04$ \\
\hline 9074 & $\begin{array}{l}\text { aromatic amino acid family catabolic } \\
\text { process }\end{array}$ & $1.51 \mathrm{E}-03$ \\
\hline 9065 & $\begin{array}{l}\text { glutamine family amino acid catabolic } \\
\text { process }\end{array}$ & $1.43 \mathrm{E}-02$ \\
\hline 10120 & camalexin biosynthetic process & 2.15E-02 \\
\hline 6558 & L-phenylalanine metabolic process & $1.97 \mathrm{E}-02$ \\
\hline \multicolumn{3}{|c|}{ Developmental processes: } \\
\hline 9901 & anther dehiscence & $1.00 \mathrm{E}-02$ \\
\hline 48544 & recognition of pollen & $1.40 \mathrm{E}-02$ \\
\hline \multicolumn{3}{|l|}{ Others: } \\
\hline 6468 & protein phosphorylation & 9.85E-04 \\
\hline 71702 & organic substance transport & $1.28 \mathrm{E}-02$ \\
\hline 7165 & signal transduction & $1.57 \mathrm{E}-02$ \\
\hline 51865 & protein autoubiquitination & $2.15 E-02$ \\
\hline \multicolumn{3}{|c|}{ Molecular function: } \\
\hline 43565 & sequence-specific DNA binding & 5.53E-09 \\
\hline 5506 & iron ion binding & $2.42 \mathrm{E}-05$ \\
\hline 9055 & electron carrier activity & 4.39E-05 \\
\hline 5199 & structural constituent of cell wall & $9.06 \mathrm{E}-05$ \\
\hline 16705 & $\begin{array}{l}\text { oxidoreductase activity, acting on } \\
\text { paired donors, with incorporation } \\
\text { or reduction of molecular oxygen }\end{array}$ & $5.20 \mathrm{E}-04$ \\
\hline 19825 & oxygen binding & $6.82 \mathrm{E}-04$ \\
\hline 45735 & nutrient reservoir activity & $9.46 \mathrm{E}-04$ \\
\hline 4674 & protein serine/threonine kinase activity & $9.60 \mathrm{E}-04$ \\
\hline 16165 & lipoxygenase activity & $9.74 \mathrm{E}-03$ \\
\hline 16840 & carbon-nitrogen lyase activity & $1.12 \mathrm{E}-02$ \\
\hline
\end{tabular}

* Only GO terms of the end nodes in the network were presented.

\section{Conclusions}

C. bungeana is a perennial subnival alpine plant with high capacity of chilling and freezing resistance. In recent years, much effort has been taken in our research group to reveal the cold tolerance mechanisms of this plant at physiological and molecular levels. In this paper, we provide the first study on the transcriptome of chilling stressed seedlings of C. bungeana. We got 54,870 assembled unigenes using the Trinity de novo assembly method, and a number of chilling regulated genes were identified, providing useful resources for gene mining to improve cold tolerance of plants. Furthermore, the comparison of the functional networks of chilling regulated genes in C. bungeana and Arabidopsis provided informative results, which could help us tell the differences in cold tolerance mechanisms between $C$. bungeana and Arabidopsis. We found that karrikins might be new plant growth regulators involved in chilling tolerance of plants. Although gene expressions at the transcriptional level were stimulated by chilling in both $C$. bungeana and Arabidopsis, their activation networks were different as suggested by TFs analysis. Cold acclimation mechanism may be weak in or absent from C. bungeana because of lack of some CBFs orthologs. Alternatively, protein phosphorylation and ubiquitination may serve as more rapid and flexible cold tolerance mechanisms for C. bungeana to adapt to the harsh cold environments.

\section{Methods}

Plant material, growth conditions and treatments

Plant regeneration of C. bungeana via somatic embryogenesis was performed as described by Wang et al. [76]. Callus was induced from matured seeds of $C$. bungeana on MS medium containing $4.0 \mathrm{mg} \mathrm{l}^{-1} \mathrm{GA} 3,2.0 \mathrm{mg} \mathrm{l}^{-1}$ NAA, and $2.0 \mathrm{mg} \mathrm{l}^{-1}$ 2,4-D. Seedlings were regenerated from callus on MS medium containing 3\% sucrose in about 3 weeks. Regenerated plants were transferred to new MS medium containing 3\% sucrose and grown at $22^{\circ} \mathrm{C}$ with a $14 \mathrm{~h}$ photoperiod under $80 \mu \mathrm{mol} \mathrm{m} \mathrm{m}^{-2} \mathrm{~s}^{-1}$ fluorescent light for further 7 days before treatments. For each treatment, ten plants (roots, shoots and leaves) were randomly pooled and treated in MS liquid medium containing $3 \%$ sucrose at $22^{\circ} \mathrm{C}$ or $2^{\circ} \mathrm{C}$. Chilling stress was initiated 4 hours after dawn (zeitgeber time 4; ZT4). Upon the treatment time reaching 24 hours, both control and chilling stressed samples were collected at the same time point and frozen immediately with liquid nitrogen.

\section{RNA extraction, CDNA library construction and RNA sequencing}

For RNA sequencing, total RNA was extracted using TRIzol reagent (Invitrogen, Carlsbad, CA, USA). The quality of total RNA was checked using the NanoDrop 


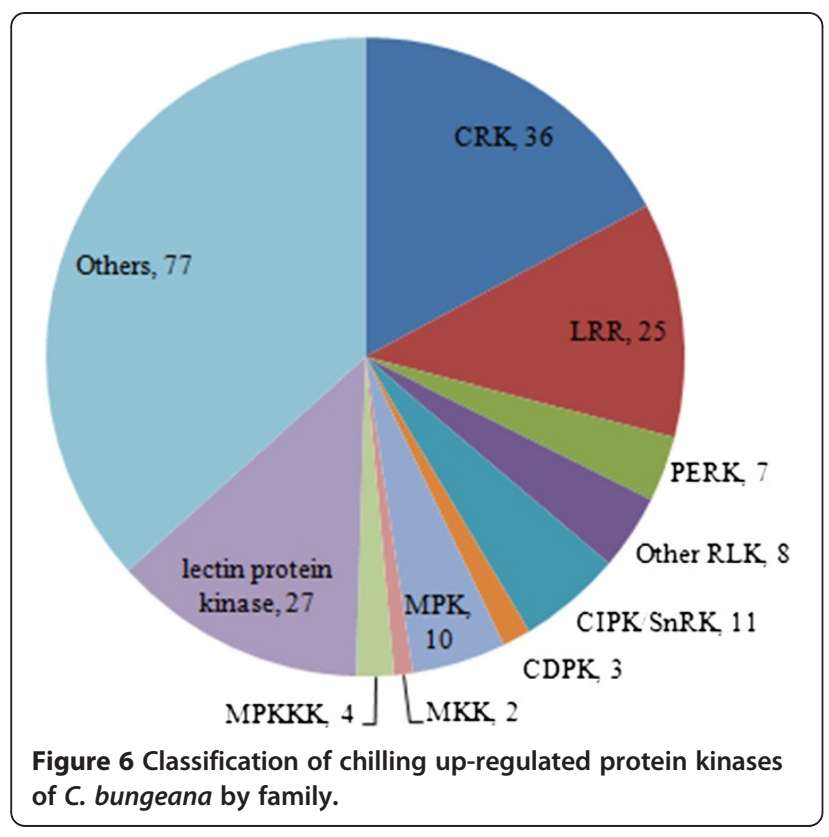

Spectrometer (ND-1000 Spectrophotometer, Peqlab) and the Agilent 2100 Bioanalyzer (RNA Nano Chip, Agilent). High quality RNA samples (20 $\mu \mathrm{g}$ each) were sent to Beijing Genomics Institute (BGI, Shenzhen) for cDNA libraries construction and sequencing using Illumina HiSeq $^{\text {tm }}$ 2000. The cDNA library construction method and Illumina deep-sequencing processes were the same as described by $\mathrm{Xu}$ et al. [45].

\section{De novo assembly and sequences clustering}

The Trinity method [42] was used for de novo assembly of the clean reads to generate Trinity unigenes, with optimized k-mer length of 25. Then, the Trinity unigenes of both libraries were clustered with TGICL software [43] to get sequences (final unigenes) that cannot be extended on either end. De novo assembly was also conducted with SOAPdenovo software [44] with optimized k-mer length of 41.

Files containing the raw read sequences and their quality scores are available from the National Center for Biotechnology Information (NCBI) Short Read Archive with the accession number: SRA054354. The Trinity unigenes have been deposited in the Transcriptome Shotgun Assembly Sequence Database (TSA) at NCBI [GenBank: JW988067-JW999999, KA000001-KA089547].

\section{Expression analysis and identification of differentially expressed genes (DEGs)}

Clean reads were mapped back to assembled unigenes with SOAPaligner (version 2.21) [44] allowing maximum 2 mismatches. The reads with unique best hits were counted for each unigene. The expression level of $C$. bungeana unigene was normalized by the number of RPKM (reads per kilobase exon region per million mapped reads) [77]. Since Illumina sequencing method is highly sensitive, we only used a subset of unigenes which presented in both sequencing libraries with a minimal RPKM of 1 for DEGs analysis. Unigene expressions were analyzed using DEGseq R package [78] with MARS method. Chilling-regulated DEGs were identified with Benjamini $q<0.001$ [79] and normalized fold change $>=2$.

For comparisons, two public available data sets of Arabidopsis were used in our study. One data set (referred to ATH-SR, means Arabidopsis short reads) was RNA sequencing data downloaded from NCBI Sequence Read Archive (SRA) database (http://www.ncbi.nlm.nih.gov),
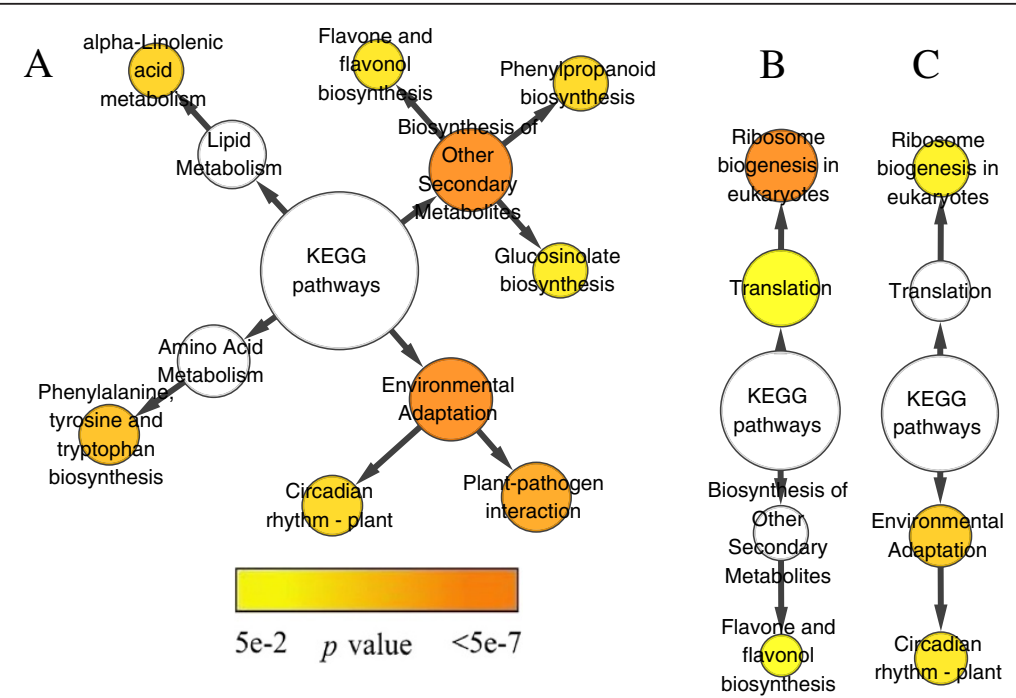

Figure 7 KEGG pathway network of chilling up-regulated DEGs. A, C. bungeana; B, ATH-SR; C, ATH-MA. Node size represented gene number in node and node filled color represented $p$ value. 


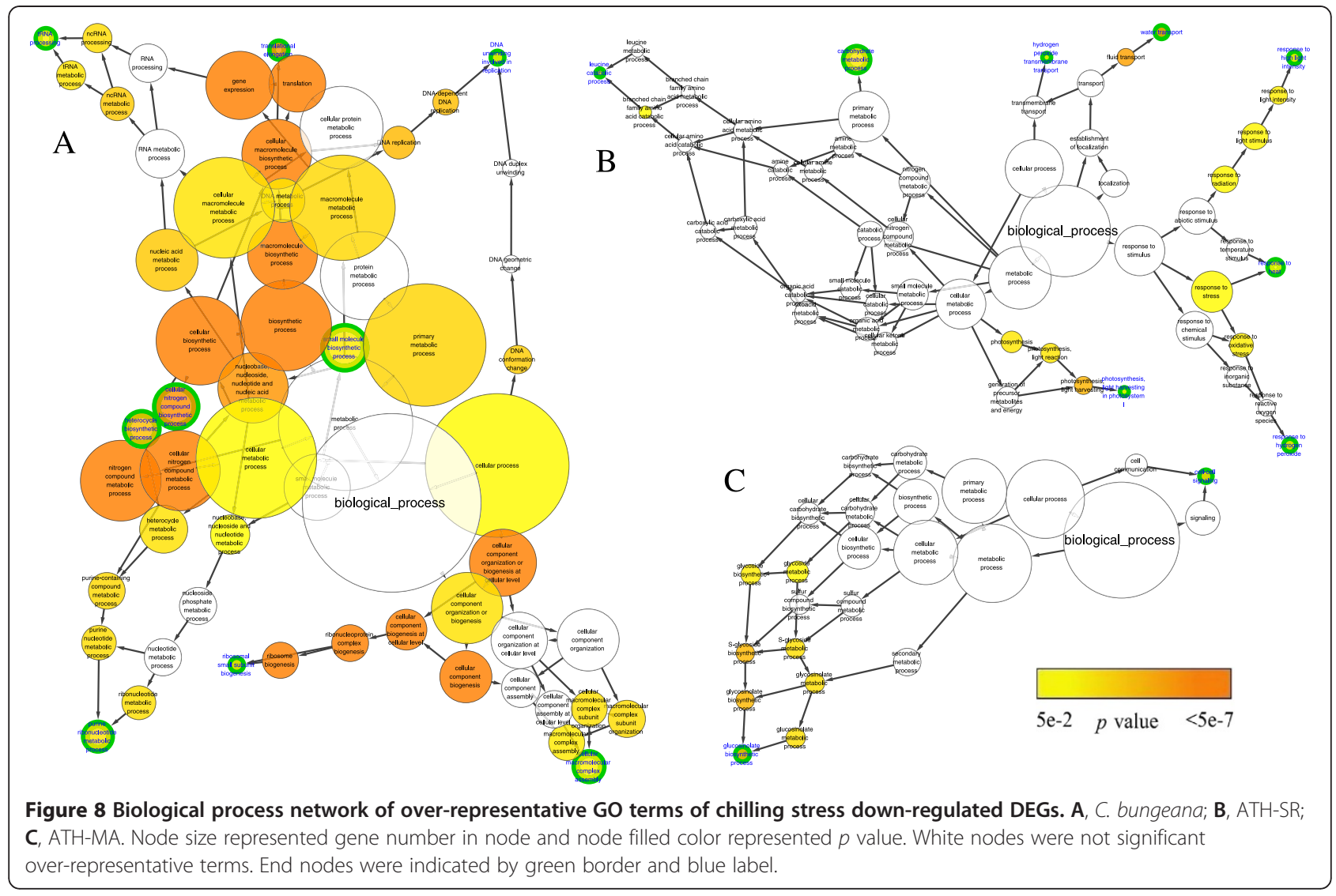

including a chilling-treated sample $\left(4^{\circ} \mathrm{C}\right.$; SRA accession: SRX006193) and a control $\left(21^{\circ} \mathrm{C}\right.$; SRA accession: SRX006704) sample [80]. After removing low quality reads (polyA/T/G/C sequences) and trimming off four NTs of both ends, all clean reads (28 NTs long) were mapped to Arabidopsis cDNAs (TAIR10) with SOAPaligner. DEGs identification was the same as described above. The DEGs and indentified gene with RPKM $>=1$ were listed in Additional file 6.

The other data set (referred to ATH-AR, means Arabidopsis array) was Affimetrix microarray data set (Expression Set: ME00325) [81] downloaded from TAIR (http:// www.arabidopsis.org). Only cel files for 4 chilling-treated samples ( 2 for roots and 2 for shoots, 24-hour chillingtreated) and 4 control samples were used here. The cel files were imported into $\mathrm{R}$ and analyzed with Affy package [82]. Root and shoot arrays were analyzed separately. Probes expressed in all root or shoot arrays were considered to be presented probes (by mas 5 present calls). Differential expressed probes were identified using mas5 method of with FDR corrected $p<0.05$ and fold change $>=2$ and mapped to Arabidopsis transcripts. The gene lists of roots and shoots were combined together to get chilling regulated DEGs and all expressed genes for further analysis (Additional file 7).

\section{Functional categorization}

We used two methods for functional categorization of unigenes.

To get general gene ontology (GO) annotations for all unigenes, sequences longer than $200 \mathrm{bp}$ were aligned to three public databases (NR, Swiss-Prot and KEGG) by BLASTX with E-value < =1e-5. The GO annotations for the top blast hits were retrieved with Blast2GO program [83] and used to annotate the C. bungeana transcripts. GO functional classification was performed by WEGO website tool [84].

For GO terms and KEGG pathways enrichment analysis, we used the Arabidopsis annotation systems. Briefly, the sequences of all unigenes were aligned against Arabidopsis peptide database (TAIR10) using BLASTX program with E-value $<=1 \mathrm{e}-5$. The top blast hits were considered to be putative orthologous genes (POGs). Then the C. bungeana unigenes were annotated with GO (downloaded from TAIR) and KEGG annotations (ath00001.keg, from http://www.kegg.jp/) for Arabidopsis POGs, respectively. The ontology (GO and KEGG) enrichment was analyzed with BiNGO plugins [49] for Cytoscape [85], using hypergeometric test for statistical analysis. For $p$ value correction, we used rigorous Bonferroni correction method. The cutoff $p$ value 


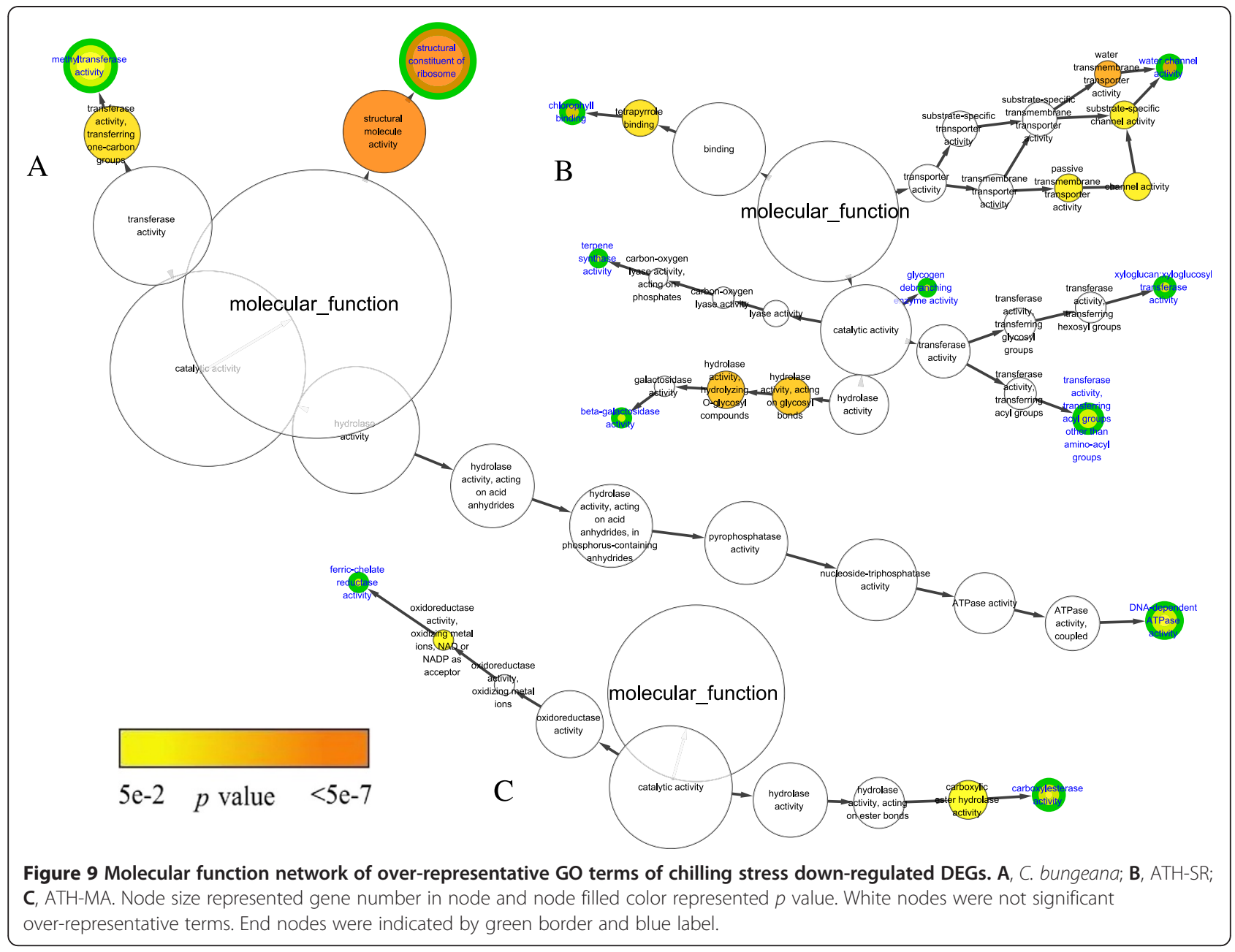

after correction was 0.05 . For ATH-SR dataset, since the stressed sample was pooled from seedlings subjected to various periods of chilling-treated $(1,2,5,10,24$ hours of stressed) [80], the expressions of DEGs specific to a certain stage might have been "normalized". Therefore, to get more information, we used FDR method instead of Bonferronic method for $p$ value correction to find over-representative terms with BiNGO.

\section{Quantitative real-time PCR (qPCR)}

The gene-specific primers for real-time PCR analysis were designed using Primer Premier (version 5.0) software (PREMIER Biosoft). The specifities of primer pairs were confirmed by BLASTN with non-redundant unigene set of $C$. bungeana transcripts and the PCR products were checked by agrose electrophoresis to ensure single band amplifications. The primer sequences for all unigenes used in this study were listed in Additional file 8.

For qPCR analysis, total RNAs were extracted from control or chilling stressed C. bungeana seedlings (two biological repeats) with TRIZOL reagent and treated (20 $\mu$ g RNA) with $1 \mathrm{U}$ DNase (TAKARA, Japan). cDNA was transcribed reversely from $1 \mu \mathrm{g}$ of DNase-treated RNA with 200U M-MLV reverse transcriptase (Promega, USA) and analyzed with Platinum SYBR green qPCR supermix-UDG reagents (Invitrogen).

Before quantification of unigenes, the geNorm method was applied to select stable expressed unigenes in the four samples as reference genes [86]. A total of 8 candidate reference unigenes were selected for reference genes screening, including an ACTIN2 ortholog, 3 unigenes showed stable expression levels in RNA-seq analysis and the other 4 unigenes were orthologs of recommended Arabidopsis reference genes [87]. The information of reference gene candidates and the geNorm analysis results were shown Additional file 8. Three unigenes (CBT10872/AT3G60800, CBT28565/AT5G27630 and CBT12464/AT2G28390) expressed most stably in control and chilling-treated samples were selected and used for all qPCR analysis.

qPCR analysis was performed with three technical repeats for each sample. The relative expression levels of unigenes were normalized with the three selected reference genes with Pfaffl method $[86,88]$. 


\section{Availability of supporting data}

The data sets supporting the results of this article are available in the NCBI GenBank repository, [http://www. ncbi.nlm.nih.gov/sites/nuccore?term=104929[BioProject]], and in the NCBI SRA repository, [http://www.ncbi.nlm. nih.gov/sra?term=SRA054354].

\section{Additional files}

\section{Additional file 1: Complete list of unigenes with BLASTX hits. \\ Additional file 2: Complete list of chilling regulated DEGs identified with fold change $>=2$ and $q<0.001$. \\ Additional file 3: Complete list of chilling regulated DEGs identified with fold change $>=2, q<0.001$ and RPKM $>=1$. \\ Additional file 4: Chilling up-regulated TFs. 1. List of chilling up- regulated TFs in both ATH-SR and ATH-MA. 2. List all chilling up-regulated TFs in Arabidopsis (ATH-SR or ATH-MA). 3. All chilling up-regulated TFs (orthologs) in C. bungeana. \\ Additional file 5: List of chilling up-regulated protein serine/ threonine kinase in $\mathrm{C}$. bungeana. \\ Additional file 6: List of chilling regulated DEGs and all expressed genes of ATH-SR. 1. List of chilling up-regulated DEGS (SR). 2. List of chilling down-regulated DEGS (SR). 3. List all genes RPKM $>=1$ (SR). \\ Additional file 7: List of chilling regulated DEGs and all expressed genes of ATH-MA. 1. List of chilling up-regulated DEGs (MA). 2. List of chilling down-regulated DEGs (MA). 3. List all expressed genes (MA). \\ Additional file 8: Primers and reference gene selections. 1. Primers for reference gene selection. 2. Primers for qPCR verification. 3. Unigenes for $\mathrm{qPCR}$ reference gene selection. 4. geNorm results of reference gene selection.}

\section{Abbreviations}

COR: Cold-responsive; CBF: CRT binding transcription factor; RNA-seq: RNA sequencing; DEG: Differentially expressed gene; GO: Gene ontology; KEGG: Kyoto Encyclopedia of Genes and Genomes; POG: Putative orthologous gene; qPCR: Quantitative real-time PCR; TF: Transcription factor.

\section{Competing interests}

The authors declare that they have no competing interests.

\section{Authors' contributions}

ZZ designed the experiments and drafted the manuscript (zgzhao@lzu.edu. cn). LT contributed to data analysis and interpretation (tanll@|zu.edu.cn). CD prepared plant materials and carried out qPCR analysis (tsdcy2006@126.com). HZ participated in plant preparations (zhanghua@lzu.edu.cn). QW provided part of the financial support (qbwu@lzb.ac.cn). LA conceived of the study and provided financial support for the project (lizhean@lzu.edu.cn). All authors read and approved the final manuscript.

\section{Acknowledgements}

This work was funded by the Major Project of Cultivating New Varieties of Transgenic Organisms (2009ZX08009-029B), State Key Laboratory of Frozen Soil Engineering (SKLFSE201004) and the National Science Foundation of China (31070353).

\section{Author details}

${ }^{1}$ Key Laboratory of Cell Activities and Stress Adaptations, Ministry of Education, School of Life Sciences, Lanzhou University, Lanzhou 730000, China. ${ }^{2}$ State Key Laboratory of Frozen Soil Engineering, Cold and Arid Regions Environmental and Engineering Research Institute, Chinese Academy of Sciences, Lanzhou 730000, China.

Received: 23 July 2012 Accepted: 19 November 2012

Published: 21 November 2012

\section{References}

1. Fu XY, Chang JF, An LZ, Zhang MX, Xu SJ, Chen T, Liu YH, Xin H, Wang JH: Association of the cold-hardiness of Chorispora bungeana with the distribution and accumulation of calcium in the cells and tissues. Environ Exp Bot 2006, 55:282-293.

2. Liu YJ, Zhao ZG, Si J, Di CX, Han J, An LZ: Brassinosteroids alleviate chilling-induced oxidative damage by enhancing antioxidant defense system in suspension cultured cells of Chorispora bungeana. Plant Growth Regul 2009, 59:207-214.

3. Shi $Y$, An $L$, Zhang $M$, Huang $C$, Zhang $H$, Xu S: Regulation of the plasma membrane during exposure to low temperatures in suspension-cultured cells from a cryophyte (Chorispora bungeana). Protoplasma 2008, 232:173-181.

4. Guo FX, Zhang MX, Chen Y, Zhang WH, Xu SJ, Wang JH, An LZ: Relation of several antioxidant enzymes to rapid freezing resistance in suspension cultured cells from alpine Chorispora bungeana. Cryobiology 2006, 52:241-250.

5. Ding $S$, Huang $C L$, Sheng HM, Song $C L$, Li YB, An LZ: Effect of inoculation with the endophyte Clavibacter sp. strain Enf12 on chilling tolerance in Chorispora bungeana. Physiol Plant 2011, 141:141-151.

6. Wu JM, Zhao ZG, Xing H, Guo HP, Li WX, An LZ, XU SJ, Chen T: Effects of freezing on plasma membrane $\mathrm{H}+-$ ATPase of the callus from Chorispora bungeana. Biol Plant 2007, 51:229-234.

7. Guy CL: Cold accelimation and freezing stress tolerance: role of protein metabolism. Annu Rev Plant Biol 1990, 41:187-223.

8. Thomashow MF: Plant cold acclimation: freezing tolerance genes and regulatory mechanisms. Ann Rev Plant Physiol Plant Mol Biol 1999, 50:571-599.

9. Steponkus PL: Cold acclimation of hedera helix: evidence for a two phase process. Plant Physiol 1971, 47:175-180.

10. Koster KL, Lynch DV: Solute accumulation and compartmentation during the cold acclimation of puma rye. Plant Physiol 1992, 98:108-113.

11. Kamata T, Uemura M: Solute accumulation in heat seedlings during cold acclimation: contribution to increased freezing tolerance. Cryo Letters 2004, 25:311-322.

12. Kushad MM, Yelenosky G: Evaluation of polyamine and proline levels during low temperature acclimation of citrus. Plant Physiol 1987 84:692-695.

13. Evert DR, Weiser CJ: Relationship of electrical conductance at two frequencies to cold injury and acclimation in cornus stolonifera Michx. Plant Physiol 1971, 47:204-208.

14. Miller RW, de la Roche I, Pomeroy MK: Structural and functional responses of wheat mitochondrial membranes to growth at low temperatures. Plant Physiol 1974, 53:426-433.

15. Pomeroy MK, Raison JK: Maintenance of membrane fluidity during development of freezing tolerance of winter wheat seedlings. Plant Physiol 1981, 68:382-385.

16. Toivio-Kinnucan MA, Chen HH, Li PH, Stushnoff C: Plasma membrane alterations in callus tissues of tuber-bearing solanum species during cold acclimation. Plant Physiol 1981, 67:478-483.

17. Taulavuori E, Tahkokorpi M, Taulavuori K, Laine K: Anthocyanins and glutathione S-transferase activities in response to low temperature and frost hardening in Vaccinium myrtillus (L.). J Plant Physiol 2004, 161:903-911.

18. Korn M, Peterek S, Mock HP, Heyer AG, Hincha DK: Heterosis in the freezing tolerance, and sugar and flavonoid contents of crosses between Arabidopsis thaliana accessions of widely varying freezing tolerance. Plant Cell Environ 2008, 31:813-827.

19. Carvallo MA, Pino MT, Jeknic Z, Zou C, Doherty CJ, Shiu SH, Chen TH, Thomashow MF: A comparison of the low temperature transcriptomes and CBF regulons of three plant species that differ in freezing tolerance: Solanum commersonii, Solanum tuberosum, and Arabidopsis thaliana. J Exp Bot 2011, 62:3807-3819.

20. Stockinger EJ, Gilmour SJ, Thomashow MF: Arabidopsis thaliana CBF1 encodes an AP2 domain-containing transcriptional activator that binds to the C-repeat/DRE, a cis-acting DNA regulatory element that stimulates transcription in response to low temperature and water deficit. Proc Natl Acad Sci U S A 1997, 94:1035-1040.

21. Jaglo-Ottosen KR, Gilmour SJ, Zarka DG, Schabenberger O, Thomashow MF: Arabidopsis CBF1 overexpression induces COR genes and enhances freezing tolerance. Science 1998, 280:104-106. 
22. Liu Q, Kasuga M, Sakuma Y, Abe H, Miura S, Yamaguchi-Shinozaki K, Shinozaki K: Two transcription factors, DREB1 and DREB2, with an EREBP/AP2 DNA binding domain separate two cellular signal transduction pathways in drought- and low-temperature-responsive gene expression, respectively, in Arabidopsis. Plant Cell 1998, 10:1391-1406.

23. Medina J, Bargues M, Terol J, Perez-Alonso M, Salinas J: The Arabidopsis CBF gene family is composed of three genes encoding AP2 domaincontaining proteins whose expression Is regulated by low temperature but not by abscisic acid or dehydration. Plant Physiol 1999, 119:463-470.

24. Shinwari ZK, Nakashima K, Miura S, Kasuga M, Seki M, Yamaguchi-Shinozaki K, Shinozaki K: An Arabidopsis gene family encoding DRE/CRT binding proteins involved in low-temperature-responsive gene expression. Biochem Biophys Res Commun 1998, 250:161-170.

25. Gilmour SJ, Sebolt AM, Salazar MP, Everard JD, Thomashow MF: Overexpression of the Arabidopsis CBF3 transcriptional activator mimics multiple biochemical changes associated with cold acclimation. Plant Physiol 2000, 124:1854-1865.

26. Doherty CJ, Van Buskirk HA, Myers SJ, Thomashow MF: Roles for Arabidopsis CAMTA transcription factors in cold-regulated gene expression and freezing tolerance. Plant Cell 2009, 21:972-984.

27. Franklin KA, Whitelam GC: Light-quality regulation of freezing tolerance in Arabidopsis thaliana. Nat Genet 2007, 39:1410-1413.

28. Dong MA, Farre EM, Thomashow MF: Circadian clock-associated 1 and late elongated hypocotyl regulate expression of the C-repeat binding factor (CBF) pathway in Arabidopsis. Proc Natl Acad Sci U S A 2011, 108:7241-7246.

29. Pino MT, Skinner JS, Park EJ, Jeknic Z, Hayes PM, Thomashow MF, Chen TH: Use of a stress inducible promoter to drive ectopic AtCBF expression improves potato freezing tolerance while minimizing negative effects on tuber yield. Plant Biotechnol J 2007, 5:591-604.

30. Benedict C, Skinner JS, Meng R, Chang Y, Bhalerao R, Huner NP, Finn CE, Chen $\mathrm{TH}$, Hurry V: The CBF1-dependent low temperature signalling pathway, regulon and increase in freeze tolerance are conserved in Populus spp. Plant Cell Environ 2006, 29:1259-1272.

31. Hsieh TH, Lee JT, Yang PT, Chiu LH, Charng YY, Wang YC, Chan MT: Heterology expression of the Arabidopsis C-repeat/dehydration response element binding factor 1 gene confers elevated tolerance to chilling and oxidative stresses in transgenic tomato. Plant Physiol 2002, 129:1086-1094.

32. Dubouzet JG, Sakuma Y, Ito Y, Kasuga M, Dubouzet EG, Miura S, Seki M, Shinozaki K, Yamaguchi-Shinozaki K: OsDREB genes in rice, Oryza sativa L., encode transcription activators that function in drought-, high-salt- and cold-responsive gene expression. Plant J 2003, 33:751-763.

33. Vogel JT, Zarka DG, Van Buskirk HA, Fowler SG, Thomashow MF: Roles of the CBF2 and ZAT12 transcription factors in configuring the low temperature transcriptome of Arabidopsis. Plant J 2005, 41:195-211.

34. Fowler S, Thomashow MF: Arabidopsis transcriptome profiling indicates that multiple regulatory pathways are activated during cold acclimation in addition to the CBF cold response pathway. Plant Cell 2002 14:1675-1690

35. Jaglo KR, Kleff S, Amundsen KL, Zhang X, Haake V, Zhang JZ, Deits T, Thomashow MF: Components of the Arabidopsis C-repeat/dehydrationresponsive element binding factor cold-response pathway are conserved in Brassica napus and other plant species. Plant Physiol 2001, 127:910-917.

36. Yun KY, Park MR, Mohanty B, Herath V, Xu F, Mauleon R, Wijaya E, Bajic VB, Bruskiewich $\mathrm{R}$, de Los Reyes $\mathrm{BG}$ : Transcriptional regulatory network triggered by oxidative signals configures the early response mechanisms of japonica rice to chilling stress. BMC Plant Biol 2010, 10:16.

37. Greenup AG, Sasani S, Oliver SN, Walford SA, Millar AA, Trevaskis B: Transcriptome analysis of the vernalization response in barley (Hordeum vulgare) seedlings. PLOS One 2011, 6:e17900.

38. Zhou D, Zhou J, Meng L, Wang Q, Xie H, Guan Y, Ma Z, Zhong Y, Chen F, Liu J: Duplication and adaptive evolution of the COR15 genes within the highly cold-tolerant Draba lineage (Brassicaceae). Gene 2009, 441:36-44.

39. von Meijenfeldt N: Unraveling the cold response in Draba. PhD thesis. The Netherlands: Universiteit van Amsterdam, The Institute for Biodiversity and Ecosystem Dynamics (IBED) and the Swammerdam Institute for Life Sciences (SILS); 2010

40. Archambault A, Stromvik MV: PR-10, defensin and cold dehydrin genes are among those over expressed in Oxytropis (Fabaceae) species adapted to the arctic. Funct Integr Genomics 2011, 11:497-505.
41. Blanc G, Agarkova I, Grimwood J, Kuo A, Brueggeman A, Dunigan DD, Gurnon J, Ladunga I, Lindquist E, Lucas S, et al: The genome of the polar eukaryotic microalga Coccomyxa subellipsoidea reveals traits of cold adaptation. Genome Biol 2012, 13:R39.

42. Grabherr MG, Haas BJ, Yassour M, Levin JZ, Thompson DA, Amit I, Adiconis $X$, Fan L, Raychowdhury R, Zeng Q, et al: Full-length transcriptome assembly from RNA-Seq data without a reference genome. Nat Biotechnol 2011, 29:644-652.

43. Pertea G, Huang X, Liang F, Antonescu V, Sultana R, Karamycheva S, Lee Y, White J, Cheung F, Parvizi B, et al: TIGR Gene Indices clustering tools (TGICL): a software system for fast clustering of large EST datasets. Bioinformatics 2003, 19:651-652.

44. Li R, Yu C, Li Y, Lam TW, Yiu SM, Kristiansen K, Wang J: SOAP2: an improved ultrafast tool for short read alignment. Bioinformatics 2009, 25:1966-1967

45. Xu DL, Long H, Liang JJ, Zhang J, Chen X, Li JL, Pan ZF, Deng GB, Yu MQ: De novo assembly and characterization of the root transcriptome of Aegilops variabilis during an interaction with the cereal cyst nematode. BMC Genomics 2012, 13:133.

46. Nakayama K, Okawa K, Kakizaki T, Honma T, Itoh H, Inaba T: Arabidopsis Cor15am is a chloroplast stromal protein that has cryoprotective activity and forms oligomers. Plant Physiol 2007, 144:513-523.

47. Qiu Q, Ma T, Hu Q, Liu B, Wu Y, Zhou H, Wang Q, Wang J, Liu J: Genomescale transcriptome analysis of the desert poplar, Populus euphratica. Tree Physiology 2011, 31:452-461.

48. Wong MM, Cannon $\mathrm{CH}$, Wickneswari R: Identification of lignin genes and regulatory sequences involved in secondary cell wall formation in Acacia auriculiformis and Acacia mangium via de novo transcriptome sequencing. BMC Genomics 2011, 12:342.

49. Maere S, Heymans K, Kuiper M: BiNGO: a Cytoscape plugin to assess overrepresentation of gene ontology categories in biological networks. Bioinformatics 2005, 21:3448-3449.

50. Ishitani M, Xiong L, Stevenson B, Zhu JK: Genetic analysis of osmotic and cold stress signal transduction in Arabidopsis: interactions and convergence of abscisic acid-dependent and abscisic acid-independent pathways. Plant Cell 1997, 9:1935-1949.

51. Yeh S, Moffatt BA, Griffith M, Xiong F, Yang DS, Wiseman SB, Sarhan F, Danyluk J, Xue YQ, Hew CL, et al: Chitinase genes responsive to cold encode antifreeze proteins in winter cereals. Plant Physiol 2000, 124:1251-1264.

52. Nelson DC, Riseborough JA, Flematti GR, Stevens J, Ghisalberti EL, Dixon KW Smith SM: Karrikins discovered in smoke trigger Arabidopsis seed germination by a mechanism requiring gibberellic acid synthesis and light. Plant Physiol 2009, 149:863-873.

53. Scott IM, Clarke SM, Wood JE, Mur LA: Salicylate accumulation inhibits growth at chilling temperature in Arabidopsis. Plant Physiol 2004, 135:1040-1049.

54. Ding CK, Wang CY, Gross KC, Smith DL: Jasmonate and salicylate induce the expression of pathogenesis-related-protein genes and increase resistance to chilling injury in tomato fruit. Planta 2002, 214:895-901.

55. Huang $X, L i J$, Bao F, Zhang X, Yang S: A gain-of-function mutation in the Arabidopsis disease resistance gene RPP4 confers sensitivity to low temperature. Plant Physiol 2010, 154:796-809.

56. Monroy AF, Sangwan $V$, Dhindsa RS: Low temperature signal transduction during cold acclimation: protein phosphatase $2 \mathrm{~A}$ as an early target for cold-inactivation. Plant J 1998, 13:653-660.

57. Monroy AF, Sarhan F, Dhindsa RS: Cold-Induced Changes in Freezing Tolerance, Protein Phosphorylation, and Gene Expression (Evidence for a Role of Calcium). Plant Physiol 1993, 102:1227-1235.

58. Teige M, Scheikl E, Eulgem T, Doczi R, Ichimura K, Shinozaki K, Dangl JL, Hirt $\mathrm{H}$ : The MKK2 pathway mediates cold and salt stress signaling in Arabidopsis. Mol Cell 2004, 15:141-152.

59. Wen JQ, Oono K, Imai R: Two novel mitogen-activated protein signaling components, OsMEK1 and OsMAP1, are involved in a moderate low-temperature signaling pathway in rice. Plant Physiol 2002, 129:1880-1891.

60. Saijo $Y$, Hata S, Kyozuka J, Shimamoto K, Izui K: Over-expression of a single $\mathrm{Ca} 2+-$ dependent protein kinase confers both cold and salt/drought tolerance on rice plants. Plant J 2000, 23:319-327.

61. Saijo Y, Kinoshita N, Ishiyama K, Hata S, Kyozuka J, Hayakawa T, Nakamura T, Shimamoto K, Yamaya T, Izui K: A Ca(2+)-dependent protein kinase that 
endows rice plants with cold- and salt-stress tolerance functions in vascular bundles. Plant Cell Physiol 2001, 42:1228-1233.

62. Abbasi F, Onodera H, Toki S, Tanaka H, Komatsu S: OsCDPK13, a calciumdependent protein kinase gene from rice, is induced by cold and gibberellin in rice leaf sheath. Plant Mol Biol 2004, 55:541-552.

63. Tsai TM, Chen YR, Kao TW, Tsay WS, Wu CP, Huang DD, Chen WH, Chang CC, Huang HJ: PaCDPK1, a gene encoding calcium-dependent protein kinase from orchid, Phalaenopsis amabilis, is induced by cold, wounding, and pathogen challenge. Plant Cell Rep 2007, 26:1899-1908.

64. Kim KN, Cheong YH, Grant JJ, Pandey GK, Luan S: CIPK3, a calcium sensorassociated protein kinase that regulates abscisic acid and cold signal transduction in Arabidopsis. Plant Cell 2003, 15:411-423.

65. Huang C, Ding S, Zhang H, Du H, An L: CIPK7 is involved in cold response by interacting with CBL1 in Arabidopsis thaliana. Plant Sci 2011, 181:57-64.

66. Dong $\mathrm{CH}$, Agarwal M, Zhang $\mathrm{Y}$, Xie Q, Zhu JK: The negative regulator of plant cold responses, HOS1, is a RING E3 ligase that mediates the ubiquitination and degradation of ICE1. Proc Natl Acad Sci U S A 2006, 103:8281-8286

67. Michael TP, Salome PA, McClung CR: Two Arabidopsis circadian oscillators can be distinguished by differential temperature sensitivity. Proc Natl Acad Sci U S A 2003, 100:6878-6883.

68. Mikkelsen MD, Thomashow MF: A role for circadian evening elements in cold-regulated gene expression in Arabidopsis. Plant J 2009, 60:328-339.

69. Fowler SG, Cook D, Thomashow MF: Low temperature induction of Arabidopsis CBF1, 2, and 3 is gated by the circadian clock. Plant Physiol 2005, 137:961-968.

70. Gerloff ED, Richardson T, Stahmann MA: Changes in Fatty acids of alfalfa roots during cold hardening. Plant Physiol 1966, 41:1280-1284.

71. Palta JP, Whitaker BD, Weiss LS: Plasma Membrane Lipids Associated with Genetic Variability in Freezing Tolerance and Cold Acclimation of Solanum Species. Plant Physiol 1993, 103:793-803.

72. Williams JP, Khan MU, Mitchell K, Johnson G: The effect of temperature on the level and biosynthesis of unsaturated fatty acids in diacylglycerols of Brassica napus leaves. Plant Physiol 1988, 87:904-910.

73. Kodama H, Hamada T, Horiguchi G, Nishimura M, Iba K: Genetic enhancement of cold tolerance by expression of a gene for chloroplast [omega]-3 fatty acid desaturase in transgenic tobacco. Plant Physiol 1994 105:601-605.

74. Nishida I, Murata N: Chilling sensitivity in plants and cyanobacteria: the crucial contribution of membrane lipids. Annu Rev Plant Physiol Plant Mol Biol 1996, 47:541-568.

75. Wu J, Zhao Z, An L, Liu Y, Xu S, Gao D, Zhang Y: Inhibition of glutathione synthesis decreases chilling tolerance in Chorispora bungeana callus. Cryobiology 2008, 57:9-17.

76. Wang J, An L, Wang R, Yang D, Si J, Fu X, Chang J, Xu S: Plant regeneration of Chorispora bungeana via somatic embryogenesis. In Vitro Cell Dev Biol Plant 2006, 42:148-151.

77. Mortazavi A, Williams BA, McCue K, Schaeffer L, Wold B: Mapping and quantifying mammalian transcriptomes by RNA-Seq. Nat Methods 2008, 5:621-628.

78. Wang L, Feng Z, Wang X, Zhang X: DEGseq: an R package for identifying differentially expressed genes from RNA-seq data. Bioinformatics 2010, 26:136-138.

79. Benjamini $Y$, Hochberg $Y$ : Controlling the false discovery rate: a practical and powerful approach to multiple testing. J R Stat Soc Ser B 1995, 57:289-300.

80. Filichkin SA, Priest HD, Givan SA, Shen R, Bryant DW, Fox SE, Wong WK, Mockler TC: Genome-wide mapping of alternative splicing in Arabidopsis thaliana. Genome Res 2010, 20:45-58.

81. Kilian J, Whitehead D, Horak J, Wanke D, Weinl S, Batistic O, D'Angelo C, Bornberg-Bauer E, Kudla J, Harter K: The AtGenExpress global stress expression data set: protocols, evaluation and model data analysis of UV-B light, drought and cold stress responses. Plant J 2007, 50:347-363.

82. Gautier L, Cope L, Bolstad BM, Irizarry RA: affy-analysis of Affymetrix GeneChip data at the probe level. Bioinformatics 2004, 20:307-315.

83. Conesa A, Gotz S, Garcia-Gomez JM, Terol J, Talon M, Robles M: Blast2GO: a universal tool for annotation, visualization and analysis in functional genomics research. Bioinformatics 2005, 21:3674-3676.
84. Ye J, Fang L, Zheng H, Zhang Y, Chen J, Zhang Z, Wang J, Li S, Li R, Bolund L: WEGO: a web tool for plotting GO annotations. Nucleic Acids Res 2006 34:W293-297.

85. Shannon P, Markiel A, Ozier O, Baliga NS, Wang JT, Ramage D, Amin N, Schwikowski B, Ideker T: Cytoscape: a software environment for integrated models of biomolecular interaction networks. Genome Res 2003, 13:2498-2504.

86. Vandesompele J, De Preter K, Pattyn F, Poppe B, Van Roy N, De Paepe A Speleman F: Accurate normalization of real-time quantitative RT-PCR data by geometric averaging of multiple internal control genes. Genome Biol 2002, 3:RESEARCH0034.

87. Czechowski T, Stitt M, Altmann T, Udvardi MK, Scheible WR: Genome-wide identification and testing of superior reference genes for transcript normalization in Arabidopsis. Plant Physiol 2005, 139:5-17.

88. Pfaffl MW: A new mathematical model for relative quantification in real-time RT-PCR. Nucleic Acids Res 2001, 29:e45.

doi:10.1186/1471-2229-12-222

Cite this article as: Zhao et al.: Deep-sequencing transcriptome analysis of chilling tolerance mechanisms of a subnival alpine plant, Chorispora bungeana. BMC Plant Biology 2012 12:222

\section{Submit your next manuscript to BioMed Central and take full advantage of:}

- Convenient online submission

- Thorough peer review

- No space constraints or color figure charges

- Immediate publication on acceptance

- Inclusion in PubMed, CAS, Scopus and Google Scholar

- Research which is freely available for redistribution 